\title{
Spiritual Exercises in Epictetus: \\ Difficult but Justified
}

by

Michael Tremblay

A thesis submitted to the Faculty of Graduate and Postdoctoral Affairs in partial fulfillment of the requirements for the degree of

Master of Arts

in

Philosophy

Carleton University

Ottawa, Ontario

(C) 2016, Michael Tremblay 


\begin{abstract}
:
The aim of this thesis is to provide a new interpretation about the role played by spiritual exercises in Epictetus' program of moral therapy, in response to Brennan (2003) who holds that they may potentially conflict with Epictetus' intellectualism. I argue that spiritual exercises are intended to cause us to assimilate theory by causing one to form specific beliefs that are in accordance with theory. Understood this way, any sort of tension seems to resolve itself. I rely upon the work that Braicovich (2012) has done on this question, and go further, ultimately demonstrating that all three of Epictetus' spiritual exercises can be explained coherently when understood as aiding in the assimilation of theory. I conclude by proposing that Epictetus thought of Stoics like athletes in training for whom spiritual exercises are essential to staying fit and ready to perform.
\end{abstract}




\section{Acknowledgements:}

It gives me great pleasure to express my gratitude to my supervisor, Professor Annie Larivée, whose unique approach to philosophy, passion for teaching, and demands for excellence have both facilitated this thesis and inspired me to be a better academic and philosopher.

I would like to thank my parents, Peter Tremblay and Sandy Wooley, as well as my sister, Alison Tremblay, for their constant support and enthusiasm when it comes to the writing of this thesis. It is only because of them that I have the confidence and opportunity to pursue my passion for philosophy.

I would like to also thank the following people who have contributed to the process of writing this thesis: My Grandmother Peg Wooley, for her feedback on my rough drafts and our discussions about the merit of Stoicism; Patricia Pajunen for always willing to debate the specifics of Stoic theory; Timmy Grainger and Jonathan Reardon for their insightful comments about the style and substance of my drafts; Melanie White for her impeccable help with editing and her constant support for all of my endeavors; the members of class PHIL4004/5600, for allowing me to present an early version of this thesis, and for providing excellent feedback. 


\section{Table of Contents:}

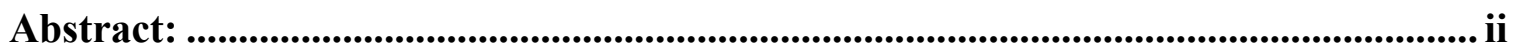

Acknowledgements: ............................................................................................................ iii

Table of Contents:.............................................................................................................. iv

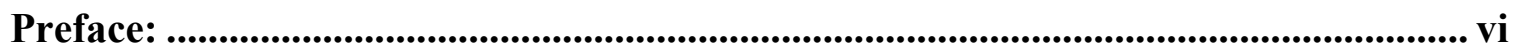

1 Chapter: Epictetus' Intellectualism and Psychology .................................................. 1

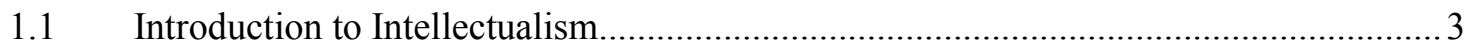

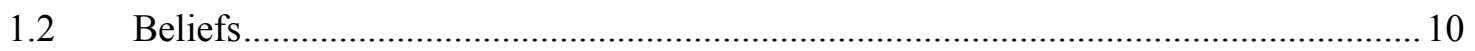

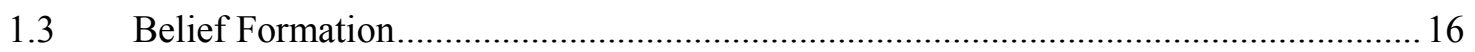

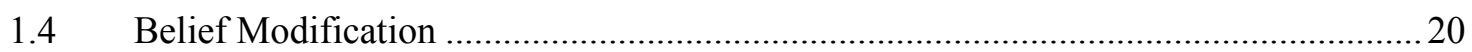

2 Chapter: Spiritual Exercises and Intellectualism .................................................... 26

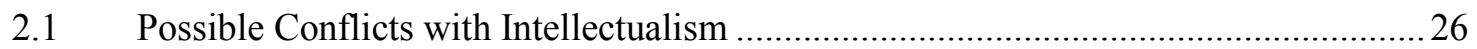

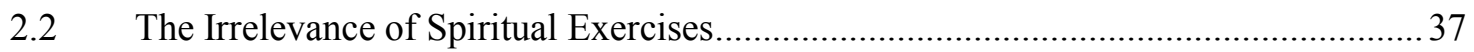

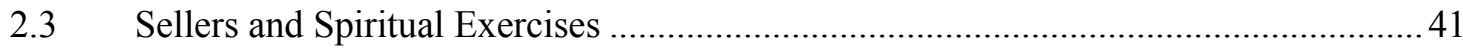

3 Chapter: Spiritual Exercises Reimagined ................................................................. 48

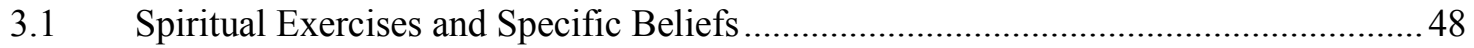

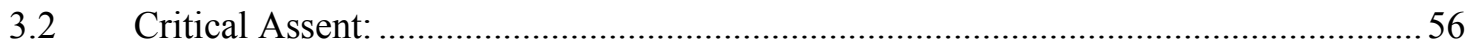

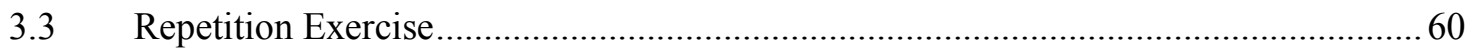

4 Chapter: Habituation Exercise and Questioning Exercise ..................................... 70

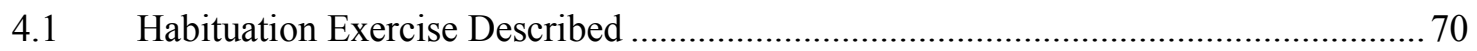

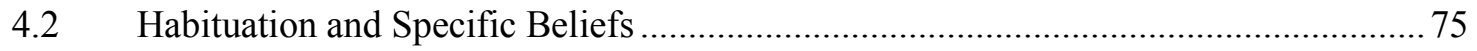

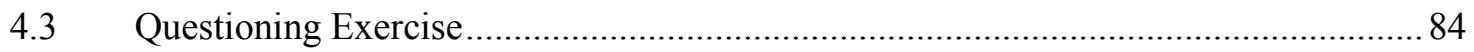

4.4 Questioning Exercise and Specific Beliefs............................................................. 90

5 Chapter: The Athlete Analogy ..................................................................................... 95 


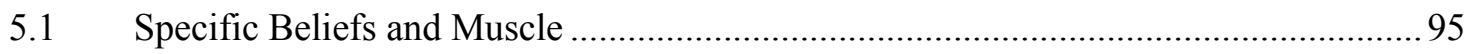

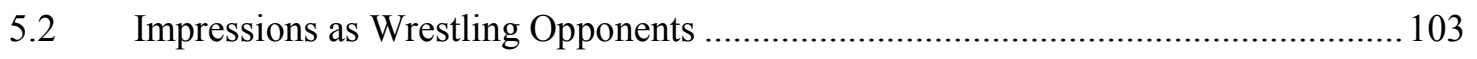

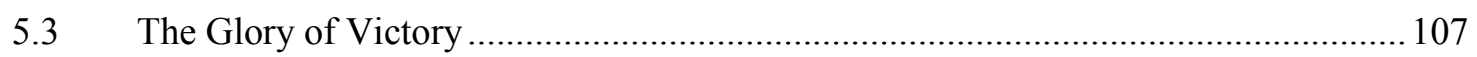

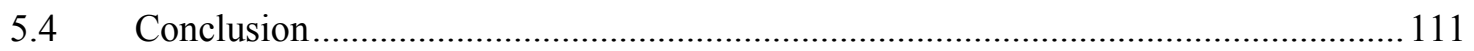

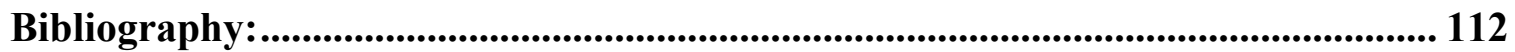




\section{Preface:}

The aim of this thesis is to provide insight into the exact role and nature that spiritual exercises have in the philosophy of Epictetus. More specifically, it is a direct response to the paper "Stoic Moral Psychology", within which Tad Brennan argues that Epictetus' reliance upon repetition to modify belief is inconsistent or incompatible with the unified reasoning soul he endorses as a Stoic. To resolve this problem, I will provide an interpretation of spiritual exercises within Epictetus which does not conflict with his conception of the self as wholly rational.

Brennan's concern is that the exercises in Epictetus seem to be, at least prima facie, a non-cognitive modification strategy which is essential or necessary for the formation of correct beliefs (Moral Psychology, 2003, 278). Brennan also argues that "it is a plausible rule of thumb that what can only be altered by non-rational means is a nonrational state" (Moral Psychology, 279). Brennan's argument is a problem because Epictetus' reliance upon repetition would seem to force him to hold the view that beliefs are at least in part non-cognitive, which is not something a Stoic would endorse.

However, Brennan is not steadfast in his view. By acknowledging that this conflict is founded from a prima facie viewpoint, and that his criticisms are plausible, but not certain, Brennan is inviting further dialogue and discussion of the issue. Other philosophers have proposed interpretations of spiritual exercises which do not conflict with intellectualism. I will look at Sellers' (2007) and Cooper's (2007) accounts but deem them to be insufficient.

My aim is to construct an account that takes the best parts from Sellers (2007) while acknowledging the problems raised by Brennan (2003) and Cooper (2007). 
My thesis will be divided into five chapters:

1. Epictetus' Intellectualism and Psychology

2. Spiritual Exercises and Intellectualism

3. Spiritual Exercises Reimagined

4. The Habituation Exercise and the Questioning Exercise

5. The Athlete Analogy

In Chapter 1, I will outline Epictetus' intellectualism and, using quotes from the primary text as well as secondary sources, identify what precisely this intellectualism commits him to, such as the impossibility of akrasia or weakness of will.

In Chapter 2, I will focus on how spiritual exercises possibly relate to Epictetus' intellectualism commitments. This first section will discuss Brennan's (2003) concerns about the potential conflict between these exercises and a wholly rational conception of the mind, while the next two sections will examine Cooper's (2007) and Sellers' (2007) interpretations of spiritual exercises respectively.

In Chapter 3, I will put forward my own original account of the purpose or role of spiritual exercises within Epictetus. I will then examine a paper by Braicovich (2012) in which he discusses a specific exercise, the Repetition Exercise, in great detail. His account of this specific exercise fits perfectly with my interpretation of spiritual exercises in general and it will lay the foundation for examining the other two exercises.

In Chapter 4, I will then look at the other two spiritual exercises present in Epictetus, which I will call the Habituation Exercise and the Questioning Exercise. I will explain how they are intended to contribute towards our moral progress, and demonstrate how they fit my interpretation of spiritual exercises. 
Finally, in Chapter 5, I will discuss the analogy Epictetus makes between a philosopher and an athlete. While Epictetus is not always explicit about what he believed, I hold that this analogy shows my interpretation of spiritual exercises to be in accordance with how Epictetus conceived of the process of moral progress. 


\section{Chapter: Epictetus' Intellectualism and Psychology}

In this thesis, I will refer to secondary sources for clarification and additional insight. However, the bulk of my interpretation will be focused on a primary source, the Discourses by Epictetus.

I am focusing my attention primarily on the Discourses because I believe it is the best resource available for obtaining accurate insight into Epictetus' philosophy. Epictetus did not write anything himself, but rather had his lessons transcribed by his pupil, Arrian.

Despite not being written by Epictetus, there is still little to no reason to believe that these works are not accurate representations of what Epictetus taught and believed to be true (Dent, xvii; Dobbin, vii-viii; Long, 2002, 41). There are only two remaining works written by Arrian and attributed to Epictetus. These works are the Discourses and The Handbook. In addition, there remain 36 fragments. Of these writings, only the Discourses are conceived of as being a comprehensive and in-depth representation of the philosophy of Epictetus. Unlike The Handbook, much of the Discourses are written in the form of a dialogue, either real or hypothetical, between teacher and student. Not only is this an accurate representation of how Epictetus instructed, but such a dialectic form is also a part of his pedagogical method. Much like Socrates, the dialectical form may have been considered by Epictetus as an essential part of how to teach philosophy (Long, 2002, 86). All of this is lost when we rely too heavily upon the fragments and The Handbook.

In addition, fragments by their very nature cannot be systematic, and often they cannot even be contextualized. And while the The Handbook is a complete work, it was conceived of by Arrian as a kind of summary of the Discourses which would contain the same ideas, but lack detailed justifications, explanations, and dialogues about these ideas 
(Dobbin, vii; Long, 2002, 9). As such, while it is still a valuable text, ${ }^{1}$ ideally designed for the practicing Stoic to quickly reference, it does not lend itself as well to an in depth philosophical reading as the Discourses does (Dobbin, xxiii).

Thus by focusing predominantly on the Discourses, I will be able to examine the text to a level of depth not possible if I extend my focus too broadly. And additionally, I will not be misrepresenting the philosophy of Epictetus. If anything, I believe I am being more faithful to Epictetus by focusing on the Discourses.

The translation I will using is the 1995 Everyman's edition of The Discourses, The Handbook, Fragments, translated by Robin Hard. I am using this edition because it is comprehensive, including every chapter of the Discourses that have survived. Other editions exclude chapters of the Discourses deemed superfluous, unnecessary, or even repetitive. $^{2}$

I will also be working heavily from Tad Brennan's book The Stoic Life: Emotions, Duties, and Fate, which outlines very well the basic principles of Stoic psychology. As will be shown, I do in fact endorse Brennan's conception of Stoic psychology. It is only upon the role that spiritual exercises play within that psychology that our views diverge.

${ }^{1}$ A fundamental part of the value of The Handbook will become apparent in later chapters. Specifically, it seems to be a tool explicitly designed to aid in the Repetition Exercise I will discuss in detail in Chapter 3.

${ }^{2}$ Given that part of my topic is focused upon the important role that repetition held for Epictetus, it is interesting to note that contemporary philosophy and translators do not hold repetition to the same high esteem. There might be a serious problem here if in the process of attempting to adapt material for contemporary study and consumption translators actually remove an aspect of Epictetus' philosophy he would have deemed to be essential. For example Dobbin, translator of the Penguin Edition of the Discourses and Selected Writings, admits to removing repetitive passages: “...I have omitted from my translation of Books III and IV a number of discourses that I judge to be little more than restatements of ideas developed to better effect elsewhere" (xxiii). 
The goal of this chapter is descriptive in nature. I hope to outline Epictetus' intellectualism, and to determine what exactly this intellectualism entails, and what it commits him to. I will then develop what influence this intellectualism has had on how Epictetus conceives of human psychology, more specifically the nature of beliefs, belief formation, and belief modification. As such, this chapter will be divided into four parts:

i. Introduction to Intellectualism

ii. Beliefs

iii. Belief Formation

iv. Belief Modification

A feature of studying the Discourses that is unavoidable is that due to the text's nature as a series of lessons, Epictetus is not always explicit about his conception of the mind, especially when it comes to specific and technical aspects of human psychology. However, I am confident that even though he is not explicit, we can reasonably infer what he holds to be true based on what he does explicitly make clear, and based on his membership in a philosophical school that did have other members who were more direct in their explanation of technical concepts. As such, where there is no reason to think that Epictetus disagreed or diverged from orthodox Stoicism, I will refer to secondary literature which describes Stoic intellectualism and psychology as a whole.

\subsection{Introduction to Intellectualism}

An accurate understanding of intellectualism in Epictetus is necessary for two reasons. First, it is necessary to properly understand the merit behind Brennan's concerns 
of inconsistency within the work of Epictetus, and secondly it is necessary to properly understand my proposed solution to these concerns.

Roughly speaking, intellectualism is the idea that the self is entirely rational and that knowledge is sufficient for virtue. This stands in stark opposition to the conception of the self famously put forward by Plato in the Republic, in which the self is divided and has non-rational aspects. Epictetus endorsed intellectualism, which puts him in line with most of his Stoic contemporaries and predecessors (Long, 2002, 17). ${ }^{3}$ A wholly rational self is one of the main tenants of Epictetus' philosophy and is an essential presupposition of most of his ethical theories and arguments.

For the sake of brevity and focus, this introduction will only examine two parts of Epictetus' intellectualism. Firstly, that Epictetus' particular form of intellectualism conceives of the mind as being comprised of one faculty within which there are three distinct occurrences. And secondly, that self-identity is limited exclusively to our rationality.

In the Discourses, there is only one faculty that Epictetus makes reference to when describing the mind. This is the faculty of reason. Then there are three mental occurrences within that faculty. These are impressions, the act of assent, and the impulse to act (Braicovich, 315).

Beginning with impressions, they are a mental idea or conception of something. They usually carry with them a kind of propositional content that such and such is the case

\footnotetext{
${ }^{3}$ While there is an ongoing interpretive debate as to whether the Stoics conceived of the self as being monistic or comprised of many faculties (Inwood, 1985, 28) what is important for this discussion is that we can be sure that Epictetus conceived of the self as entirely rational.
} 
(Nussbaum, Therapy, 374). It is due to this propositional content that they can be deemed true or false. Often impressions take the form of a specific mental picture, in fact "most impressions arise from our senses, or from our memories of sensory episodes—seeing out the window, or closing my eyes and remembering what I saw" (Brennan, Stoic Life, 52). However, impressions are not limited to things that can be easily visualized. They can also be any descriptive proposition, such as the idea that two and two makes four. They can also have normative value. I may have the descriptive impression that it is day or night, but I can also have the normative impression that ice cream is good, or that physical suffering is bad.

It is important to note that impressions are not at all separate or distinct from the mind. They are very much a part of it. As Brennan describes, "according to the Stoics, an impression is just a piece of matter in a certain configuration; it is my mind, altered in accordance with the thing that makes the impression on it" (Brennan, Stoic Life, 54-55). ${ }^{4}$ Epictetus recognizes this when he asks "So, what is rationality itself? A structure made up of various impressions" $(1.20 .5) .^{5}$

The second occurrence within the mind is the act of assent. The faculty of reason reflects upon these impressions and has one of three choices. It assents to them as being true, dissents from them as false, ${ }^{6}$ or withholds assent until a later time (Braicovich, 316 ).

\footnotetext{
${ }^{4}$ Long offers a similar definition of an impression: "anything at all that 'appears' to us, anything that constitutes an instance of our awareness" (Long 1996b, 274) ${ }^{5}$ This is a translation by Long, not by Hard, but I believe Long's translation better represents what I am attempting to show here, namely that our mind is composed of nothing but impressions, and our judgements about them.

${ }^{6}$ How one would dissent to an impression as false is to assent to its negation. If the impression is "Diotima walks", then the negation that I assent to will be "Not: Diotima
} 
All aspects of our psychology, be it beliefs, emotions, motivations or desires, can be reduced and attributed to specific impressions, and our assent to those impressions, or lack thereof (Brennan, Stoic Life, 52).

Thus the concept of the rational faculty, and its ability to assent, is at the core of Stoic and Epictetan psychology. In the words of Brennan: "assent is the linchpin of the Stoic system. Assent is the fundamental psychological activity—more fundamental even than believing something, or desiring something” (Brennan, Stoic Life, 52).

The third aspect, the impulse to act, is derived from the kind of impression we assent to. If I assent to an impression with affective content, that assent will cause an impulse to act that motivates me towards a certain action. What determines if an impression has affective content is if it relates to an object which I value (or disvalue). If I assent to an impression that a snake is in front of me, and I also have the belief that snakes are dangerous to my health, and my health is something valuable, then my assent will motivate me to remove that danger, perhaps by killing the snake or fleeing outright.

So to provide a quick example of Epictetian psychology, imagine I hear of the death of a close friend whom I value as having a significant role in my life. I therefore have the impression that my friend has died. I then apply the faculty of reason to this impression, and assent to it as true. This impression is affective, because it concerns the status of someone to whom I have ascribed great value. Thus, I may have the impulse to grieve, with all the emotions and actions grieving entails. This grieving process is reducible to

walks". Dissent must take this strict form because to assent to a statement such as "Diotima doesn't walk", would assume the existence of Diotima, something not entailed by my dissenting to the initial impression. For further discussion on the Stoic conception of negations, and their logic in general see Bobzein (2003). 
my assent to the impression as true. If I never give assent to the impression that my friend has died, none of the accompanying beliefs, emotions, and actions will follow.

Change the example anyway you like, for Epictetus all cognitive activity can be reducible to impressions and our assent to them, or, in Epictetus' terminology, our use of the impression. In a telling passage, Epictetus defends this theory against the criticism that this is too simplistic an account to justify the complexity of human emotion:

[In reference to the Greek Tragedy Medea, in which Medea murders her children out of rage directed at her unfaithful husband] So, do such great and dreadful deeds have this as their origin, then, sense-impressions? This and no other. The Iliad consists of nothing but impressions and the use of those impressions. An impression prompted Paris to carry off the wife of Menelaus. An impression prompted Helen to follow him. If, then, an impression has caused Menelaus to feel that it was an advantage to be robbed of such a wife, what would have happened? Not only the Illiad would have been lost, but the Odyssey too. (1.28.11-13)

What Epictetus is saying is that even in a story with such complex motivations and emotions as the Illiad, all of the motivations, emotions, beliefs and desires are reducible to impressions and their use. If Menelaus had received a different impression, or had withheld assent to the impression he did have, then his emotions, beliefs, desires and motivation would have been different, and the Illiad would not have come to pass.

What makes the fact that our belief and motivations can be reducible to patterns of assent so important for Epictetus is that, as rational beings, our ability to assent is ultimately up to us. We thus possess an uncanny amount of autonomy in determining the nature of our inner life. In fact, this is the only part of our lives that can be said to be truly 
up to us, or within our power. Epictetus says in reference to the faculty of reason that "the gods have placed this alone in our own power, the most excellent faculty of all which rules all the others, the power to deal rightly with our impressions, whilst all the others they have not placed in our power" (1.1.7).

Epictetus is saying that the Gods have given us the power to assent to, or withhold assent from, our impressions, through providing a rational faculty. Power is meant in the strong sense here. We may have a degree of power over our bodies, but this is ultimately circumstantial and severely limited. Thus it is not real power. It is possible for our bodies to be chained, or maimed, or otherwise permanently altered and their function permanently impeded by things outside of our control. But when it comes to our rational faculty, even the gods may not impede us (1.1.24).

The point here is that if our complex psychological states are comprised of nothing but impressions and if we have total control over how we make use of our impressions, through control over our ability to assent, then we have control over our minds. This is one of the key concepts behind Stoicism's powerful assertion of our autonomy.

The second key aspect of Epictetus' intellectualism is that self-identity can only be attributed to our rationality. This means that Epictetus is not satisfied to just make the claim that the state of our minds are up to us. By equating our minds with our selfidentity, he goes a step further and asserts that who we are in any meaningful sense is up to us. In the following passage of the Discourses, Epictetus describes how a philosopher who understands that their identity is their rationality would respond to the threat of physical imprisonment: "[The philosopher is asked to betray a secret] - I will not betray it; for this is in my own power. - 'Then I will fetter you.' --- What are you saying, man? 
Fetter me? You will fetter my leg; but not even Zeus himself can get the better of my choice" (1.1.22-24).

The point here is two-fold. First, Epictetus is clarifying that our body is not our self. The tyrant thinks he is threatening to fetter the philosopher but, as Epictetus points out, a philosopher's leg is not the same thing as that philosopher. As Epictetus says earlier in the same chapter it is crucial to "not forget that this body is not your own" (1.1.11). What he wants us to realize is that our identity actually resides in our rationality, or our ability to choose which impressions we assent to and which we do not. And this ability to choose is necessarily free from outside control.

Rationality is not arbitrarily chosen as the self. The very reason we can say that our ability to assent is our own, but our bodies are not, is because one is up to us and the other is not. In other words, for Epictetus we can only say that something is ours if it is up to us, if we have control over it. And the only thing that is up to us is the use of our rational faculty.

This brings up a paradox of intellectualism. If we have total power over our rationality, and our minds is entirely rational, and our mind is all we are, then why do we so often not feel in control of ourselves? Why are we ever unhappy, or disappointed or angry if we have the freedom to will ourselves to be otherwise? For Epictetus the answer is obvious. We internally limit ourselves. We remove our natural freedom through poor choices. This is quite concisely summarized by A.A. Long:

[For Epictetus] You and I are not our bodies, nor even do we own our bodies. We, our essential selves, are our volitions. In that domain, and only in that domain, we have the 
possibility of freedom. This freedom, though it is our inalienable nature, is typically jeopardized, because people identify themselves with their bodies and all manner of external things----other persons, commodities, political powers, and so forth. Real lasting freedom is not available to humans in any of these domains; consequently, those who pursue them are constrained, thwarted, and emotionally enslaved as a result of the mistaken attachments they make. (Epictetus, 29)

Humans have the tendency to be ignorant, and mistakenly self-identify with things outside of their rationality. This causes suffering, because we do not have control over those things, nor were we meant to have control of them. The nature of Epictetus' ethics is thus a response to this human tendency. Through practice, education and rational argument, his ethical theory aims to correct our mistaken beliefs such that we only attach value to ourselves, or our ability to choose.

Now that an introduction to intellectualism has been provided, I will move to describing Epictetus' conception of our psychology. As this thesis deals with how repetition impacts belief, the important questions are: What are beliefs? How are they formed? And by what means can they come to be changed?

\subsection{Beliefs}

So what exactly are beliefs to the Stoics, and what is their nature? As described briefly above, we know that beliefs have something to do with assenting to an impression. But an important distinction needs to be established here between impressions and beliefs. Brennan provides a succinct definition for a belief: 
"Stoic Definition of Belief: a belief is an assent to an impression" (Brennan, Stoic Life, 65$)^{7}$

So first let us examine what it means for a belief to be an assent to be an impression. This means, first and foremost, that a belief is an event or an action. It is not a static state. It is not something to be carried with you, but rather something that happens. To use an example, imagine I have the belief "B" which is an assent of impression "I". What this means is that I had an impression "I", which carried with it some propositional content. This propositional content was then judged by my rational faculty, and then assented to. This "assenting", the act of my rational faculty assenting to an impression, is what " $\mathrm{B}$ " is. Beliefs are thus a kind of action, like running or throwing. This process could be as complex as dealing with trauma or tragedy, or this process could concern a trivial fact. I might taste ice cream, receive the propositional content from that impression that ice cream is good, assent to that impression, and then this act of assent would be my belief that ice cream is good.

What this definition also means is that a belief is not, and cannot, be an impression. Nor can an impression be a belief. The two are structurally distinct. As Brennan acknowledges: "states and events are completely different sorts of things; on the Stoic view an impression is a state, and a belief, because it is an assent, is an event" (Brennan, Stoic Life, 66). Recall that an impression is a configuration of the mind. It is a way the

\footnotetext{
${ }^{7}$ Nussbaum offers a similar definition: "a judgement, for the Stoics, is defined as an assent to an appearance" (Therapy, 374)
} 
mind is, a specific state of the mind. A belief by contrast is an event or action. A belief can still be temporally extended, it does not have to be instantaneous, but it cannot ever be an impression.

Despite what might seem like a simplistic explanation of beliefs, Stoics retain a complex conception of different kinds of beliefs. A belief does not have to take the form of a cold, inert proposition. It could also be a desire or even an emotion with a strong affective content. It is important to clarify here that for Epictetus my belief does not cause my emotion. Nor does my emotion cause my belief. Rather, as Nussbaum indicates, in Stoicism the relationship between emotion and belief "is one of identity: the emotion just is a certain sort of belief or judgement" (Therapy, 80). This is because the affective content unique to emotions is built straight into certain beliefs. To use an example by Nussbaum, when one acknowledges and assents to the death of a loved one whose existence seemed a necessary component of one's well-being, this assent immediately brings with it the affective force of grief. This assent does not create grief, it is grief. The "very act of assent is itself a wrenching, tearing violation of [one's] self-sufficiency and [one's] undisturbed condition" (Therapy, 380). Thus the grief, like all emotions, is a belief. It is not caused by one.

The only difference then between a belief that is not an emotion and one that is an emotion is that emotions are caused when we assent to certain kinds of impressions. We develop an emotion when we assent to "an impression that attributes a certain kind of 
value to the agent's own potential action" (Brennan, Stoic Life, 82$).{ }^{8}$ So if I place a high value on ice cream, I may be sad when I drop it and am deprived of it or jealous when my friend enjoys her own frozen treat.

This puts us in a position to properly understand how Epictetus can endorse intellectualism. Many philosophers have used emotions and their affective content as evidence that there must be a non-cognitive aspect of the mind. And it would seem that their existence poses a problem for any intellectualist. But Epictetus as a Stoic does not reject the existence of emotions. Rather, he conceives of them as being wholly cognitive, and is thus able to reconcile them with intellectualism.

Another key aspect of beliefs is that they are what contain moral value. For Epictetus, the concept of good and evil only applies to beings which are rational, because only rational beings can exercise the ability to assent upon impressions. "Plants do not even have the capacity to deal with external impressions, and therefore you do not apply the term good to them. Good requires, then, the capacity to deal with these impressions" (2.8.4). Plants and animals are amoral because they lack rationality, or the faculty that allows us to deal with impressions. As such the concept of good or bad does not even apply to them. They are morally indifferent. Rationality is required to be moral because to be good or bad is to hold correct or false beliefs. This is why Epictetus says: "What, then, is wisdom itself? Good. And what is folly? Evil" (1.20.6).

${ }^{8}$ Also Nussbaum: "The passion is itself a certain sort of assent or acknowledgement: an acknowledgement of the tremendously high importance of something beyond my control, an acknowledgement appropriately called "excessive" because it transgresses the limits prescribed by right reason for our relation to things external (Therapy, 381). 
However, it is the nature of that which is rational to be drawn to that which is true. As such it is impossible for us to hold false beliefs intentionally. "Do you think that I fall into evil voluntarily, and miss the good? Heaven forbid! What, then, is the cause of my going wrong? Ignorance" (1.26.6). Thus if I hold a false belief, I am ignorant of its falsity. I have been misled, or mistakenly thought it was true.

When Epictetus says that wisdom is good itself and folly is evil, he is not making a consequentialist point. He is not trying to say that having false beliefs will cause us to choose evil actions, like attacking the weak or committing murder. To say this would be to confuse our external actions as having moral worth. No external acts that I commit can have intrinsic value, either good or bad (Nussbaum, Therapy, 362). Rather, what he is saying is that being ignorant, or dealing with impressions improperly, is the evil. As such, having a false belief is an evil act in and of itself. In fact, it is the only kind of evil act. And having correct beliefs is the only good act. Remember that since we only have control over our rational faculty, then assent to an impression and forming the corresponding belief is the only kind of genuine choice we ever get to make. Thus our beliefs do not cause future evil or good actions in the external world. They are the evil or good actions (Nussbaum, Therapy, 365).

This is why Epictetus' ethics is focused on possessing correct belief, and less upon particular advice how to act or behave properly in particular situations. For him, to have correct beliefs is what it means to be good. The only types of actions he criticizes are those that demonstrate ignorance. In the same vein, he is also quick to criticize those who commit actions that give off the illusion of correct belief, without actually obtaining it. This is why he judges the students who brag about having read Chrysippus but cannot 
demonstrate that knowledge in their action (1.4.9-17). This is also why in situations that are matter of personal preference, he is intentionally vague in his advice. Take this passage for example from the chapter titled How is One to Preserve One's True Character in Everything?:

But to judge what is rational and irrational, we make use not only of a due estimation of the value of external things, but of what relates to each person's particular character. Thus it is reasonable to one man to hold another's chamber-pot for him, since he considers only that if he does not submit to this, he will be beaten and lose his dinner, whereas if he does hold it, he will have nothing harsh or distressing to suffer; whilst to some other man it appears insupportable, not merely to hold the pot himself, but to allow anyone else to do so. If you ask me, then, 'Shall I hold the pot or not?', I will tell you, it is a more valuable thing to get a dinner than not; and a great disgrace to be given a thrashing than not to be: so that, if you measure yourself by these things, go off and hold the pot.

'Yes, but that would be beneath me.'

It is you who are to consider that, not I: for it is you who know yourself, and what value you set upon yourself, and at what rate you sell yourself: for different people sell themselves at different prices. (1.2.7-11)

It is no issue to Epictetus how you act, as long as you hold correct beliefs. Whether you choose to hold the pot or not is irrelevant to him. There is no right answer in the question. But what you can do wrong is hold contradictory beliefs, such as simultaneously think you are above holding the pot, and choosing to hold the pot. One of these beliefs is false, and this false belief is the evil in your action, not the action itself. 
From this we can see that beliefs play an essential role in the philosophy of Epictetus. They are a kind of action or event that we have control over when we exercise our ability to assent to impressions. In fact they are the only type of action we can be said to have control over. Thus they also carry with them the entirety of our moral value. We can only be judged to be good or evil based on the beliefs we hold, not based on how we act.

\subsection{Belief Formation}

In this section, I examine Epictetus' conception of how belief formation works. This is to say that I will look at how the rational faculty assents to an impression to form a belief. I aim to show that there are certain limitations to belief formation. This is to say that due to the very nature of the faculty of reason, there are certain impressions that cannot be assented to, and thus there are certain beliefs that cannot be formed. ${ }^{9}$

According to Epictetus, there are three limitations to our freedom of belief formation. These are demonstrated well in the following passage:

What is the reason that we assent to anything?

${ }^{9}$ At first this may seem like another Stoic paradox. How can our faculty of reason be limited, if we are supposed to have total control over it? How is the inability of my mind to assent to a contradiction any different than the inability of my body to move freely through walls? Why does one type of limitation count and not the other? While this question deserves more attention than I am able to give it here, the difference would seem to be the nature of the limitation. The rational faculty is limited internally, or by itself. In other words, to knowingly assent to a contradiction goes against the very nature of rationality itself, so this is not a limitation, but a necessary function for rationality to be rationality. In contrast, the movement of our bodies are limited and constrained by external forces. There is nothing in the nature of bodies that says their movement must be constrained by external forces in order for them to qualify as bodies. As such, this kind of limitation counts as more grievous than the one imposed on our ability to assent freely. 
Its appearing to be so.

It is not possible, therefore, to assent to what appears not to be so?

Why?

Because it is the very nature of the understanding to agree to things that are true, to be dissatisfied with things that are false, and to suspend its belief in doubtful cases.

What is the proof of this?

Have the impression, if you can, that it is now night.

Impossible

Put aside the impression that it is day.

Impossible

Have, or put aside, the impression that the stars are, or are not, even in number.

Impossible.

When any one, then, assents to what is false, be assured that he does not wilfully assent to it as false (for, as Plato affirms, the soul is never voluntarily deprived of truth); but what is false appears to him to be true. (1.28.1-5)

So despite our power over our mind, there are still certain rules we must follow when forming beliefs. We must assent to what seems to be true, we cannot assent to what seems to be false, and we must suspend judgement on that which seems to be unknowable. This is a descriptive claim of what the rational faculty must do, not a normative claim about what we should do. As Epictetus says, we are confined by these limitations due to the very nature of understanding. Therefore, in so far as our faculty of reasoning is rational, it must abide by these three limitations. The concept of our rational faculty having certain limitations, or rules it must follow, is described throughout the Discourses. He mentions elsewhere that "...it is the nature of every soul to assent to what 
is true and dissent from what is false" (3.3.2). And another good example is found in the following passage:

Now every rational soul is naturally averse to contradiction: but so long as a person fails to understand that he is involved in a contradiction, there is nothing to prevent him from performing contradictory actions, but when he has come to understand it, he must necessarily renounce and avoid the contradiction, just as bitter necessity makes a man renounce what is false as soon as he perceives that it is false, though as long as he does not have that impression, he assents to it as true. (2.26.3)

It is important to appreciate that the wording used by Epictetus in all these passages is very strong. One must necessarily renounce contradictions once they are understood to be contradictory. Likewise, bitter necessity forces us to give up beliefs we understand to be false. In the previous quote, Epictetus' interlocutor described going against these necessities as "impossible". It is clear that Epictetus believes that we are literally incapable of holding such beliefs, which means that we are also incapable of coming to form such beliefs in the first place.

A distinction that should be made clear is that Epictetus is not saying we cannot hold false beliefs, only that we cannot willingly assent to an impression that we understand to be false. This leaves room for one to hold all kinds of beliefs that are false, but this must be the result of ignorance about the truth of the matter. One can only assent to a false impression because he or she mistakenly believes it to be true.

The same limitations we have on forming false beliefs, apply to forming beliefs that we know to be evil, or denying assent to beliefs we know to be true: 
Immediately the good appears, it draws the soul towards it; and by evil the soul is repelled. A soul will never reject a clear impression of good. (3.3.4)

As it is impossible to assent to an apparent falsehood, or to deny an apparent truth, so it is impossible to abstain from an apparent good. (3.7.15)

A person, then, cannot think a thing advantageous to him and not choose it. He cannot. $(1.28 .6)^{10}$

The inability to pursue what we know to be bad is a variation of our inability to assent to that which is false. Recall that Epictetus equates wisdom with the good, and evil with folly (1.20.6). Thus to knowingly pursue evil would be to willingly assent to that which is false. This would be the equivalent of wanting to do what we know we do not want to do. It is a contradiction, and thus we cannot assent to it due to the nature of our rational faculty. ${ }^{11}$

A key implication of these limitations is that current beliefs affect future belief formation. We do not confront new impressions in a vacuum. There is a kind of feedback loop between our previous epistemic history and what we come to encounter. A quote by Braicovich is worth including in full here:

\footnotetext{
${ }^{10}$ This selection of passages is in Braicovich, 322.

${ }^{11}$ Further discussion of this aspect can be found in Long, 2002, 100-104. Long refers to this as Epictetus' "Optimistic Rationalism”.
} 
Whether or not we critically examine our impressions before assenting to or rejecting them, that act is not the operation of a neutral, transcendental faculty which might be considered to be independent from our epistemic history. More importantly, it is not an evaluation of the impression in isolation. Concerning the first aspect, every act of assessing an impression is done on the basis of the judgements or opinions that constitute our soul (which are actually impressions we have assented to in the past). Concerning the second aspect, the act of examining an impression that comes to our mind is not to evaluate it in terms of logical consistency, but rather to confront it with the opinions and beliefs we hold and, by doing so, to evaluate whether it contradicts them or not. (326)

The rational faculty cannot assent to what it knows to be false and must assent to what it knows to be true. As such, what you believe to be true or false will determine what you can or cannot assent to. In other words, the beliefs you have limit your freedom to form new beliefs. When I check to see if a new belief is a contradiction, I am checking against the beliefs I currently hold. For example, Epictetus' student is unable to assent to it being night time only because he already knows it is day time. If he mistakenly was tricked into believing it to be night time, he would be just as unable to assent to it being day. Depending on the beliefs he holds about the time of day, what new beliefs he is capable of forming changes accordingly.

\subsection{Belief Modification}

The final part of Epictetus' psychology to be examined is that of belief modification. The main point I will stress is that beliefs can only be modified due to the introduction of new evidence. It is important to note that while Epictetus does not explicitly state how 
belief modification works psychologically, what I am discussing in this section will be an inference from what has been established up to this point. My explanation of "belief modification" in the upcoming section is my own contribution, which will prove crucial in trying to develop a coherent role for Epictetus' use of spiritual exercises.

First and foremost, it is important to clarify what I mean by belief modification. Because a belief is an event, it cannot be changed. Once you have assented to an impression, you cannot assent to that impression differently, or only half assent, or only assent to part of an impression. To imagine it this way would be to misunderstand what is meant by assent. Recall that we may only give assent, dissent, or withhold assent until a further time. However, what is in our power to do is to assent to a new impression concerning the same subject. So what I mean by belief modification is the process by which my opinions about a specific object or subject come to be replaced by new ones. So for example, I will refer to the process through which we go from changing our beliefs from "X", to "Not X", or vice versa, as belief modification.

It is crucial to understand how Epictetus conceives of this process, because it would seem that ethical progress requires belief modification. Everyone except the Stoic sage has false beliefs, particularly concerning the intrinsic worth of externals, and what is up to us and not up to us. In order to achieve virtue, these beliefs must be modified to be in accordance with the truth. If " $\mathrm{X}$ " represents the belief that externals are intrinsically valuable, then to achieve virtue one must go from that belief to the belief "Not X".

Now if we recall what was said in the previous section, this seems to be a difficult process. Epictetus claims we cannot assent to an impression that seems false to us. But if one endorses "X", then all impressions that represent "Not X" should seem false. This is 
what it means to believe "X", it means "Not X" must be false. So at first glance the possibility of belief modification seems problematic. It is true that one cannot assent simultaneously to both "X" and "Not X", this would be impossible within Epictetus intellectualism. However, one must keep in mind that for Epictetus beliefs are events. They are a kind of action taken by a self-reflective rational faculty. That faculty has the ability to constantly re-evaluate new evidence, and revoke assent from current beliefs. Thus while it is impossible to hold both beliefs simultaneously, an impression of "Not $\mathrm{X}$ ", if sufficiently persuasive can cause me to revoke my assent of "X". Once I have done so I am free to assent to "Not X". While our current beliefs do limit us, they do not necessarily restrict us. We can modify our beliefs; we just need sufficient rational evidence or justification to do so.

As such, belief modification is necessarily more complicated, difficult, and prolonged a process than belief formation. It is more work to change one's beliefs about " $\mathrm{X}$ ", than it is to assent to an initial impression about " $\mathrm{X}$ ". In other words, we need more evidence to modify our beliefs than we do to form new beliefs because evidence is required to cause the individual to revoke assent from the previous impression. The new evidence must provide enough reason to convince us of the falsity of our current beliefs. This is the concept of the feedback loop I mentioned at the end of the previous section.

Thus belief modification can only take place when there is sufficient evidence or reasons to cause one to re-evaluate their beliefs and ultimately revoke assent from a current belief. This evidence can come in two forms. It can either be an extremely persuasive single impression, or it can be a culmination of smaller beliefs. Imagine I have the belief "Stephen King is the best author of all time". This belief can be changed 
because of a single extreme piece of evidence, such as Stephen King releasing a terrible book. Or it can be changed by less extreme situations, such as Stephen King writing a series of average books, which, when considered in their totality, provides sufficient evidence to change my belief. However, if I am given no such evidence then my original belief will stand because it has no reason to change or be re-evaluated.

What is important to take from this is that one cannot modify a belief for no reason. Belief modification requires one to remove assent from a previously held belief, and that will always require some sort of reason or evidence. If I believe " $\mathrm{X}$ " my belief will not shift or modify to "Not X" without a cause. And this cause must be rational. Under the Epictetan picture one always needs evidence or a reason to modify belief.

To illustrate this point, let us return to the example of Epictetus' interlocutor who is unable to hold the belief that it is night time, now equipped with an understanding of how belief modification would work. We see now that he is unable to assent to the impression that it is night time because he lacks sufficient evidence to revoke his assent to the impression that it is day time. As such, he will now require a greater degree of evidence to persuade him that it is night time than he would have if he did not yet hold any belief about the time of day. For example, if one does not know what time it is, to see that it dark outside will typically be sufficient to persuade one that it is night. However, if one already believes it to be day, then to see that it is dark outside will no longer be sufficient. One would probably assume that there is an eclipse, or that a large cloud has blocked out the sun and this is why it is dark. Only extraordinary evidence could convince one otherwise, such as one's friend telling them that they fell asleep for many hours and this is why it is no longer day. 
The fact that belief modification requires so much evidence was well understood by Epictetus. This is why for him it is better to withhold assent altogether than to hold a false belief and change it later. If we endorse a falsehood instead of withholding assent we now require even greater evidence in order to persuade us of the truth. As such, he encourages a strong skepticism about incoming impressions. He says that "the first and greatest task of a philosopher is to put impressions to the test and distinguish between them, and not admit any that has not been tested" (1.20.7). It is so important to put impressions to the test, because every false impression we assent to will make it even more difficult to eventually assent to the truth.

At the end of this chapter I have provided an outline of Epictetus' Intellectualism and his Psychology. From this point we are in a position to properly explore the merits of Brennan's worries about the coherence of repetition as an exercise. 


\section{Chapter: Spiritual Exercises and Intellectualism}

This chapter will look at contemporary interpretations of Epictetus' spiritual exercises, specifically in relation to his intellectualism. The outline of this chapter is as follows: In the first section I will examine in depth the apparent conflict between these exercises and Epictetus' intellectualist commitments, as discussed by Brennan (2003). This will be done in great detail as it is the over-arching aim of this thesis to produce an interpretation of these spiritual exercises that is coherent with Epictetus' intellectualism and immune to Brennan's concerns. In the second and third sections I will outline two interpretations of spiritual exercises, put forward by Cooper (2007) and Sellers (2007) respectively, which do not conflict with Epictetus intellectualism. However, I will ultimately deem both interpretations to be unsatisfactory, as they create more interpretive problems than they solve. Finally, taking what I have learned from examining other interpretations, I will conclude by proposing a set of conditions that spiritual exercises will have to meet if they are going to play a coherent role within Epictetus' philosophy.

\subsection{Possible Conflicts with Intellectualism}

Given what has been discussed in the previous chapter, it is surprising that much of the Discourses are not concerned with theory or rational arguments. Many passages of the Discourses take a distinctly practical tone, and are focused on describing and recommending spiritual exercises for students to practice when they are interacting with the world. These exercises are discussed in a way that makes them seem essential for the students' moral progress towards becoming accomplished Stoics. 
For example, Epictetus encourages students to repeat doctrine constantly, and perpetually keep it "on-hand" and available through this repetition (3.24.101-104). He demands that when students go out into the world they examine and question everything they see (3.8.1-3). And while perhaps these internal exercises are not so surprising, Epictetus also has a series of exercises concerning a student's actions as well. As an example, he warns that we must cultivate and practice good habits in our actions and that we must train ourselves not to yield to sexual desire, or indulge in our whims (2.18.4-13).

Brennan's argument against the spiritual exercises of Epictetus is quite simple. He argues that many of these exercises employed by Epictetus seem to be non-cognitive exercises aimed at modifying beliefs through non-rational means. Unless this is shown to not be the case, such exercises are incompatible with Epictetus' conception of the mind as wholly rational, and thus we should be skeptical of his commitment to intellectualism, or the coherence of his exercises. The passage within which Brennan raises these concerns, while long, is worth including:

Theorists who view emotions as essentially irrational products of the sub-rational soul will naturally think of them as relatively unresponsive to the ministrations of reason; the Black Horse of the Phaedrus needs the whip and goad. Beliefs, by contrast, should be open (at least in principle) to modification by reasoned argumentation - that need not be the only way of changing beliefs and it need not be the fastest or most efficient method. But one would hope that for any false belief, there is a way of bringing its owner over to the truth by purely rational methods (e.g., considerations of evidence, argument, thought-experiment, and so on). Thus it is quite striking how much of the Stoic therapeutic practice involves methods that seem, at least prima facie, to be directed to the non-cognitive modification of 
non-cognitive entities... some of the methods envisioned by Epictetan askesis should prompt us to ask the general question: Can cognitive theorists help themselves to just any possible means of behavior modification, while still claiming that what they are attempting to do is to reshape beliefs?... We should at least be disappointed when the bright Socratic hope of rationally arguing our way to virtue is replaced by the grim Epictetan tedium of catechetical pushups; in time, I think we should also be deeply skeptical of the theoretical coherence of the underlying conceptions of psychology and rationality. It is a plausible rule of thumb that what can only be altered by non-rational means is a non-rational state; even if we reject it as too simplistic, we must still ask what in detail separates cognitivism of the Stoic sort from a full Platonic acceptance of irrational parts of the soul, when our means of altering the dispositions for behavior amount to the same thing in each case. (2003, Moral Psychology, 278-279)

This passage is decidedly general. It is not an attack on any specific exercise. Rather what Brennan is articulating is a call for general concern about a tension that exists within certain Stoic texts. He encourages skepticism about the coherence of those texts unless this tension is properly addressed. This tension is that some Stoics, Epictetus in particular, seem to help themselves to many exercises employed by philosophies with much different conceptions of the self. The question is this: If the Stoics believe in a wholly rational self, why do they rely so heavily upon exercises that are not rational argumentation? Under intellectualism, proper knowledge will be sufficient to motivate proper behaviour. If I act improperly it is because I lack knowledge. If I do not understand the theory, then I should not need exercises. Rather, it seems that I should need to return to that theory and study it in greater detail in an academic setting so that 
my mind comprehends it. If non-cognitive exercises can teach me something, if they can modify my beliefs in a way that the academic setting cannot, then Brennan is right to worry that something not wholly rational is going on here.

Brennan picks a particular example, to contrast with rational argumentation, which he calls "the grim Epictetan tedium of catechetical push-ups". This refers to Epictetus' repetitive dialectical form of instruction evident upon reading the Discourses. In order to teach students, Epictetus repeatedly asks the same questions with the same answers. He also insists that we repeat these answers to ourselves, as well as constantly articulate questions to ourselves, so that we may again answer them. And ultimately he insists that we make a habit of this process such that we never cease to repeatedly engage in the 'catechetical' process. ${ }^{12}$

While Brennan's worry is broad and applies to the whole of Stoicism, he chooses Epictetus as a prime example. As such, the work of Epictetus is the ideal place to start investigating this tension in greater detail.

Brennan's concern with Epictetus ${ }^{13}$ seems to rely upon three premises established through prima facie observation:

a) Spiritual exercises in Epictetus are aimed at modifying beliefs.

\footnotetext{
${ }^{12}$ For examples of this process consider passages 3.8.1-3; 3.24.101-104; the later chapters will address Epictetus' spiritual exercises and method of teaching in greater detail.

${ }^{13}$ While I will rely heavily upon Brennan, this type of worry is not unique to Brennan. For example, Johnson (2014, Page 83, Footnote 30) also articulates a similar concern: "For Epictetus an orthos logos is achieved through both learning and assiduous habituation. There is a tension for Epictetus in holding this position because intellectualism is only supposed to require knowledge (and not practice) to make certainty secure". However, I will refer back to Brennan here because he articulates the problem most succinctly and most generally.
} 
b) These spiritual exercises seem to do so through non-rational methods.

c) If something can only be modified through a non-rational method, it is at least in part non-cognitive.

If we accept these premises, then there is a big problem for Epictetus. Taken together, they imply that beliefs in Epictetus are at least partially non-cognitive. If beliefs have a non-cognitive aspect, then there is a non-cognitive aspect of the self. If this is the case, this would render Epictetus' conception of the self false. Thus, for Epictetus to both endorse intellectualism and encourage these spiritual exercises would seem contradictory and incoherent.

It is well known that Stoicism as a philosophical school takes pride in, above all else, its structure and internal consistency (Inwood, 2003, 4). While ethics was of the utmost concern to Epictetus, his ethical system of focusing on what is up to us relies upon a conception of the mind that all orthodox Stoics shared. This is the intellectualist picture. However, if our beliefs are in any way non-cognitive, Epictetus would no longer have any dichotomist means of distinguishing between beliefs and what is not up to us. In other words, if beliefs are non-cognitive, then they are not entirely rational. If they are not entirely rational, then they are not up to us in that our rational faculty is no longer able to fully determine them. If this is the case, the Stoic loses the grounds by which they claim that beliefs are different than externals. Epictetus would no longer be able to say with such conviction that our judgements are up to us and externals are not. In this way his entire ethical project would fall apart. Thus, Brennan's concern is not a trivial technical quibble. It is a fundamental problem that must be resolved in order to preserve the coherence of the entirety of Epictetus' philosophical work. 
It is essential to clarify this argument, so I have reconstructed it here:

P1) Spiritual exercises are necessary to modify certain beliefs. ${ }^{14}$

P2) Spiritual exercises modify beliefs through non-rational methods.

P3) If spiritual exercises are necessary to modify belief, and they modify belief through non-rational methods, then the self must be partially non-cognitive.

C1) The self must be partially non-cognitive (From P1 \& P2 \& P3)

P4) The self must be wholly cognitive (intellectualism)

C2) The self must be partially non cognitive AND The self must be wholly cognitive. (From C1 \& P4)

$\mathrm{C} 2$ is a contradiction. P4 must be true, in virtue of the definition of intellectualism we established previously. Therefore, if P1, P2, and P3 are true, Epictetus' spiritual exercises are shown to be incoherent with intellectualism. This is the structure of Brennan's concern. So in order to save Epictetus from incoherence, it is necessary that at least one of these three premises be demonstrated to be false. However, proving one of them to be false is necessary but not sufficient to demonstrate that spiritual exercises are coherent with intellectualism. Before we can comfortably assert any exercise's coherence some additional work needs to be done to demonstrate that each exercise can fit within the

\footnotetext{
${ }^{14}$ As mentioned previously, an important aspect of Brennan's argument is that spiritual exercises seem to be necessary to modify belief i.e. we cannot modify belief without them. Everyone will accept that non-cognitive forces can change our beliefs. This alone does not make these beliefs necessarily non-rational. For example, if one suffers from head trauma this may change their memories and beliefs. However, if the only way to change certain beliefs is through head-trauma, then we have good reason to question if those beliefs are wholly rational.
} 
framework of Epictetus' intellectualism and psychology. Only if both these things have been done may we be confident that spiritual exercises are coherent with Epictetan intellectualism, and the burden of proof then shifts upon the opposition to show otherwise.

One could seek to disprove P3. One could argue against the claim that something which can only be modified by non-rational means must be partially non-cognitive. But this is the most difficult option. This is a complex claim in the philosophy of mind, and, more importantly, it has nothing to do specifically with Epictetus or our interpretation of the Discourses. $\mathrm{P} 3$ is an issue for contemporary debate. It is not an interpretive issue. But P3 is reliant upon P2 and P1 for relevancy. If we can disprove either of these, then we do not have to argue over P3 at all.

But unfortunately, upon examining the Discourses, $\mathrm{P} 2$ and P1 do seem to be true. Beginning with P2, it does seem, to be the case that spiritual exercises must be modifying beliefs through some non-rational means. If we recall the conception of belief modification established in 1.4, we will remember that under the intellectualist picture in order for a belief about an object to change rationally we must gain new evidence to the contrary. In order for me to go from the belief that it is day to the belief that it is night I must gain some new evidence, in either the form of impressions or beliefs, that shows my belief that it is day to be false. If I do not gain additional evidence, then my belief will not change, at least not by rational means. This is not to say that the evidence must be good evidence, it does not have to be justified and true for example, but in order for someone to change their beliefs rationally they must be provided a reason. 
This invites the key question: how can any non-rational exercise possibly provide me with a rational reason? For example, how can repeating the same evidence over and over again ever give me a new reason to believe that evidence? ${ }^{15}$ This does not seem to be plausible. If I study the Stoic precepts about the indifference of externals, and fully comprehend them, and have a good understanding of logic, then this presents all the persuasive evidence that these precepts can ever have. Especially when we consider that our minds are naturally drawn to already assent to that which is true. Either this evidence will be sufficient for me to assent to that impression, thus forming the belief that externals are indifferent, or the evidence will be insufficient, and I retain my old belief. But it seems that no amount of practicing a non-rational exercise, be it internal repetition of theory or habituation of my actions, can change the rational evidence for me to endorse this claim.

Imagine someone who already understands the Stoic argument about the indifference of externals as they have learnt it in class. They are familiar with the rules of inference and logic that its structure relies upon. They are also familiar with the justifications and arguments for all of its propositions. At this point, when they consider the evidence, they either assent to it or they do not. It seems absurd under the intellectualist picture that they should be convinced because Epictetus tells them another 15 times that externals are

\footnotetext{
${ }^{15}$ One could foreseeably bite the bullet here and say that it does not modify belief. One could argue that repetition is thus useless and superfluous as a strategy in Epictetus. While this would save Epictetus from incoherence, by proving P1 false, it is a very uncharitable way to interpret him. As a school, Stoicism, and particularly Epictetus, valued practicality. What was relevant to him was that an exercise produced proper beliefs. So it is as damaging to Epictetus to say that one of his core exercises is irrelevant as it is to claim his theories to be incoherent. Cooper (2007) takes this path and I will have more to say about what I disagree with it in Section 2.2.
} 
morally indifferent, or, in the form of an exercise, asks them to repeat this precept to themselves every day. They are given no additional rational reasons to assent to this claim. And if such an exercise was sufficient, if it really was the difference between assent being given and assent being withheld, then the process of coming to modify beliefs does not seem to be very rational at all. Braicovich articulates similar concerns when it comes to these spiritual exercises:

Given that we cannot reject the truthfulness of an impression once we see it, what is the rationale behind Epictetus' demand that we expose ourselves to a reiteration of one and the same principle 'from morning till evening' (4.1.111), whether it be through his preaching or through the exercise of repeating something to ourselves over and over again? In other words: when I am confronted with a true impression, I either grasp its truth or I do not; if I do, what need is there for me to repeat it over and over to myself? What is the use of rehearsing if I have already accepted it as true (or rejected it as false)? (Braicovich, 325)

To put it another way, as discussed in Chapter 1, assenting to an impression is a kind of action performed by the rational faculty. In order for an action to be rational it must have a reason. This reason does not have to be good or justified, but it does have to be present. However, repeating a reason cannot possibly produce a new reason. If the reasons we have are sufficient we will assent and repetition is unnecessary, and if they are not sufficient, we will not assent, regardless of how much we employ repetition. Thus in order for repetition to actually modify beliefs, there must be something more going on than cognitive means allow for. If spiritual exercises work in the way Brennan thinks they do, it must be because it is playing some kind of non-cognitive role. 
Additionally, P1 seems to be true as well. It seems that spiritual exercises are necessary to modify our beliefs. Throughout the Discourses Epictetus criticizes those who focus exclusively on memorizing doctrine and reading the works of past Stoics:

'This man here', someone says, 'is already able to read Chrysippus, even by himself.' - By the gods, that is good progress you are making, man. What progress! 'Why do you make fun of him?' - And why do you distract him from an awareness of his deficiencies? Are you not willing to show him what virtue brings about, so that he may know where to seek his progress? Seek it in that place, wretch, where your task lies. And where does your task lie? In desire and aversion, that you may neither fail to attain what you desire, nor fall into what you want to avoid; in exerting your impulse to act and not to act, that you may not be liable to error; in assent and the withholding of assent, that you may not be liable to be deceived. The first areas of study are the first and most necessary. But if, trembling and lamenting all the while, you seek never to fall into misfortune, how, I ask you, are you making progress? Show me then your progress in this point. It is as if I were talking to an athlete and said, 'Show me your shoulders', and he then replied, 'Look at my jumping-weights.' That is quite enough of you and your jumping-weights: what I want to see is what the jumping-weights serve to achieve. (1.4.9-13)

Epictetus seems to be explicitly stating here that studying and reading doctrine is not enough to achieve virtue. If we are to become good Stoics we must practice and repeat these lessons in practical scenarios. We must repeatedly apply these lessons when acting. If we fail to do so we will mistakenly confuse that which helps us to be virtuous with that which makes us virtuous, like the athlete who shows off his jumping-weights but has not improved his shoulders. 
This passage seems to solidify P1 as true. Studying of Stoic doctrines and rational arguments should be the purest form of rational argumentation possible. And yet Epictetus criticizes it as insufficient for successful belief modification. Rational argument is presented as a poor way, at least by itself, to gain proper beliefs. But even more than that, as the analogy with the athlete makes clear, it is an impossible way to gain proper beliefs. If proper beliefs could be gained this way, Epictetus' criticism would not be so cutting.

Epictetus is arguing that if proper beliefs are to be acquired, the rational knowledge gained through study must be combined with a different kind of repetitive practice, a spiritual exercise. In order to form correct beliefs we must combine our perfected rational knowledge with these exercises, just as the athlete must combine his jumping-weights with the act of actually exercising his shoulders. All of this lends evidence in support of P1.

The fact that P2 and P1 have strong textual support is what makes Brennan's argument so powerful. Nonetheless, if either can be disproven we can still save Epictetus from threats of incoherence. In the following two sections, I will examine interpretations of Epictetus which do not endorse P1. Ultimately I will deem these interpretations to be unpersuasive given what is written within the Discourses. As such, for the rest of the paper I focus on disproving P2. I do this by constructing and defending an original interpretation of the role of spiritual exercises which demonstrates that they do not modify beliefs through non-rational means. Instead they do so through rational means, although in a way unique to theory. 
Brennan's mistake is to assuming that the only way spiritual exercises could modify belief is through non-rational means. It seems that he imagines spiritual exercises and their often repetitive nature as some kind of non-cognitive force that just exerts itself upon false beliefs, changing them into true beliefs regardless of our ignorance or resistance. He imagines them as an external force akin to electric-shock therapy, to use his own analogy. I hold such an interpretation to be both unfair to Epictetus, and not at all accurate as to how spiritual exercises are actually utilized.

The next two sections, 2.2 and 2.3, are dedicated to examining interpretations of spiritual exercises in Epictetus that get around this conflict with intellectualism by not endorsing P1. These interpretations are put forward by Cooper (2007) and Sellers (2007) respectively. I argue that both are ultimately insufficient and bring with them greater problems than they solve. However, they teach us much the conditions that are necessary for a fully coherent interpretation of spiritual exercises in Epictetus.

\subsection{The Irrelevance of Spiritual Exercises}

As discussed above, one possible way to remove Brennan's concerns about spiritual exercises is to demonstrate that they are not necessary to modify beliefs. Perhaps the easiest way to do that is to argue that they are superfluous, that they do not do anything at all. One could argue that spiritual exercises have been historically overvalued in our interpretations of Epictetus, and he did not rely upon them for any moral progress, let alone require them as a necessary part of belief modification. If this is what Epictetus thought, then these exercises would not conflict with his intellectualism. Cooper (2007) argues for just such an interpretation of spiritual exercises in Epictetus. Cooper argues 
that we have misunderstood the role which the lessons found in the Discourses would have for the moral progress of students. He points out that the discussions found in the Discourses would not have been the main curriculum for the students of Epictetus. Instead the main curriculum was the same as that which was standard in all Platonist and Peripatetic schools of the time, the studying of precepts, exegesis of texts, and practicing of logic. Cooper argues that what is found in the Discourses is not exercises necessary for moral progress, but rather "with only a few exceptions, ancillary and informal admonishments or protreptics, or bits of practical advice, addressed to his pupils and delivered, it would seem, in the afternoons or evenings, after the main work of the day was already completed" (Cooper, 10).

The reason then that Epictetus makes little reference to these more traditional methods of studying theory is that they would have already been covered, discussed, and their importance reinforced during the daily lessons. Thus what we see in the Discourses is a disproportional emphasis on the "bits of practical advice" which we call spiritual exercises, that we have since misconstrued as being on par with or even more important than theory for our moral progress.

As for the common passages where Epictetus seems to condemn those who focus too much on theory ${ }^{16}$, Cooper argues that Epictetus is not condemning relying exclusively on theory, he is only condemning relying upon theory studied in the wrong way. Epictetus is angry at his students for focusing on logic before they have mastered an understanding of the precepts of Stoicism, for example. As such, Cooper concludes that for Epictetus

${ }^{16}$ Such as 1.4.9-13, quoted in full in section 2.1 . 
spiritual exercises have no role in our moral progress, as opposed to some of his contemporaries. "Unlike Seneca and Marcus Aurelius, Epictetus remains fully aware and fully committed, when it comes to offering his assistance in their moral improvement, to the classic Stoic position that moral improvement simply is a matter of increased and deepened understanding of the truths of Stoic theory, and of the bases in philosophical reason on which they rest" (Cooper, 19).

Cooper's interpretation of spiritual exercises does have its benefits, such as it saves Epictetus from Brennan's concerns of incoherence. If spiritual exercises are not necessary for moral progress, or maybe do not even modify beliefs at all, then Epictetus' reference to them does not seem to necessitate a non-cognitive part of the self.

However, if we adopt Cooper's interpretation to defend against Brennan's concerns then this just seems to be trading one extreme position for another. Worse still, I believe that such an interpretation is a disingenuous representation of Epictetus' philosophy. Cooper's position would seem to have trouble making sense of much of the text. Consider the following passages:

Each man is strengthened and preserved by actions that correspond to his nature, the builder by building, the grammarian by grammatical studies, but if the latter gets into the habit of writing ungrammatically, his art will necessarily be destroyed and perish. Thus modest acts preserve the modest man, and immodest ones destroy him; faithful actions, the faithful man, and acts of the opposite nature destroy him...For this reason philosophers exhort us not to be contented with mere learning, but to add practice also, and then training. (2.9.10-13) 
For, without severe and constant training, it is not possible to ensure that our desire should not fail or our aversion should not fall into what it would avoid... (3.12.5)

From the first quote we can see that for Epictetus practice and training, our spiritual exercises, are something very different than "mere learning". Note the emphasis that Epictetus places upon our actions. Surely knowledge is important, but Epictetus states that it is also our actions that play some role in destroying or preserving us. Thus we cannot just study theory. We must also train our actions. We must go out into the world and practice spiritual exercises. They are unique in form from theory in that they involve our actions and behavior. From the second quote we can see that without this kind of training it is "not possible" to achieve part of moral virtue.

Dismissing these kinds of claims as mere "practical advice" disregards the necessary role Epictetus constantly affirms that these exercises have. It is very clear, despite what Cooper argues, that theory alone is not sufficient for moral progress in Epictetus. Brennan's concerns exist in the first place because of just how evident it is upon reading the Discourses that the exercises have some essential purpose in our moral progress. If we are to find a viable interpretation of spiritual exercises that is coherent with intellectualism, it must also be one that respects the necessary role of these exercises. To solve Brennan's problem we cannot simply throw the baby out with the bath water. 


\subsection{Sellers and Spiritual Exercises}

Before I attempt to construct my own interpretation of the role of the spiritual exercises in Epictetus, it is necessary to take the time to examine what I believe to be the best current interpretation. Sellers (2007) has developed an interpretation of spiritual exercises in Epictetus that both acknowledges their necessity and establishes a plausible role for them. ${ }^{17}$ While I ultimately disagree with parts of Sellers' position on purpose of spiritual exercises, I still think his account is the best available so far.

Sellers argues that there are two necessary parts to Epictetus' overall education program, theory and spiritual exercises: "Theory remains a necessary condition and, for Epictetus, the point of departure for philosophical education. Yet theory alone is not enough either for one to make proper philosophical progress. For that, both logos and askêsis are required" (Sellers, 16). Askêsis, meaning training, takes the form of a variety of spiritual exercises that are just as important as our studying of theory. Sellers argues that for Epictetus the student must naturally progress from theory to spiritual exercises. We must begin our education by studying theory and logic, but these are ultimately ineffective unless combined with accompanying spiritual exercises. Both are necessary for moral progress, neither is sufficient on its own, and they must be practiced in a

\footnotetext{
${ }^{17}$ As acknowledge by Sellers (2007, Page 1, Footnote 2), the main difference between his use of the term and Pierre Hadot's, is that Hadot conceives of ancient philosophy itself as a spiritual exercise, where as Sellers conceives of these exercises as just one part of a larger program which also includes rational discourse. I am working with Sellers definition as it was designed specifically to describe an aspect of Stoicism, and strikes a proper balance between not over-valuing the importance of theory, and not under-valuing Epictetus intellectualist commitments.
} 
specific order. This is because they both have unique roles. The point of theory is to learn the truth; the point of the spiritual exercises is to "digest" the truth:

Philosophical principles only attain value once they have been digested. Just as food transforms and becomes part of the body only once it has been digested, so philosophical nourishment must be digested before it can become part of the soul, transforming one's character and ultimately one's behaviour. Spiritual exercises are directed towards this process of philosophical digestion, a process that transforms the soul and translates theoretical principles into actions. (Sellers, 20)

Sellers' picture of Epictetus' teaching program is thus the following: first we learn our precepts, then we digest them through training. This digestion "transforms the soul", allowing us to implement theory into our behaviour. While Sellers never clarifies what he means by a transformation of the soul, the practical result of digestion is clear. When a theory has been digested, we act in accordance with it. Our behaviour becomes modified. It is the process through which one goes from being a student who can recite Chrysippus, to a Stoic who acts in accordance with virtue. Digestion is essential, because without it precepts have no "value", they do not yet influence our behaviour, even if we can understand them, and as such they are inert. Because of this, spiritual exercises are necessary for moral progress. Without these exercises, we cannot reflect precepts in our behaviour or actions, and our progress is stunted, permanently relegated to the purely theoretical.

When we examine the works of Epictetus there is a lot of textual evidence supporting such an interpretation. Digestion is not a term created by Sellers, it is one 
employed by Epictetus constantly. And in the text it does seem that digestion refers to a necessary process that must be undergone before we can implement theory into action:

Never call yourself a philosopher, nor talk a great deal amongst laymen about philosophical principles, but do what follows from those principles...For sheep do not bring their fodder to the shepherds to show much they have eaten, but digest their food internally, and produce wool and milk externally. And so you likewise should not display your principles to laymen, but rather show them the actions that result from these principles once they have been digested. (Handbook, 46)

It is one thing to hoard up bread and wine in a store-cupboard, and another to eat it. What is eaten is digested, distributed and becomes nerves, flesh, bones, blood, a fine complexion, ease of breathing. Whatever is hoarded up is ready, indeed, whenever you have a mind to show it; but no further use to you than the mere reputation that you have for possessing it. (2.9.18)

These passages both have the same meaning. Epictetus is warning us not to show off our theoretical knowledge, but rather to digest it and turn it into something valuable. The point of eating fodder is not to brag about what you have eaten, nor is the purpose of a store-cupboard to show off all the bread you have collected. The purpose of food is to digest it, to turn that digested food into a desirable by-product, like wool or flesh and bones. Likewise the point of theory is to be digested, and turn that digested theory into virtuous behaviour. Thus, Sellers argues, for Epictetus theory requires digestion in order to be valuable, or at least achieve its full value. Theory only shows its worth if you can 
demonstrate the "actions that result from these principles once they have been digested" (Handbook, 46).

Continuing the analogy, Epictetus warns that if we do not take the time to properly digest theory, it will be rejected by our minds, just as a stomach will vomit undigested food:

Those who have learned precepts as mere theory want to vomit them up immediately, just as people with weak stomachs do with their food. Digest your precepts first, and you will not vomit them up in this way; otherwise they really do turn to vomit, tainted matter unfit to eat. Then show us some change that results from those precepts in your own ruling faculty... (3.21.1-3)

So not only must theory be digested to yield value, theory also requires digestion in order not to be rejected. Without digestion, even the best theory will be "unfit to eat". Thus, Sellers concludes, while theory is necessary for moral progress in Epictetus it can never be sufficient on its own. Theory will always require a second component, spiritual exercises that enable digestion.

Sellers' interpretation has a lot of merit. Unlike Cooper's, it recognizes the necessary role of spiritual exercises, but it also defends against Brennan's concerns of incoherence with intellectualism. ${ }^{18}$ Recall that Brennan was concerned that spiritual

\footnotetext{
${ }^{18}$ However it is vulnerable to another kind of conflict with intellectualism. If spiritual exercises, often taking forms that have nothing to do with rational argumentation, have the sole purpose of motivating proper behaviour, and they are not just beneficial but absolutely necessary for Epictetus, then belief can no longer be said to be sufficient to
} 
exercises seem to modify belief through non-rational means. However, if the aim of spiritual exercises is not to modify belief, but rather to modify behaviour, then there no longer seems to be a problem if they do not take the form of rational argumentation.

I agree that both theory and training are necessary for Epictetus, and that the purpose of training is to allow for the "digestion" of theory. Where my interpretation diverges with Sellers is that I disagree that the purpose of digestion is to modify our behaviour to be in accordance with theory. I recognize that this is a by-product of digestion or an indication that digestion is occurring, but it cannot be the reason for digestion. It cannot be the case for two main reasons.

The first reason I disagree with such a portrayal of digestion is that there is no way that digestion can be essential for moral progress if its only purpose is to change our external actions so that they correspond to the theory we have learnt. As previously stated, for Epictetus wisdom is sufficient for virtue. This is a point that he makes just as explicit as the necessity for spiritual exercises. As such, proper external actions are not necessary for virtue, nor in anyway inherently good. Rather they are only good because they represent our internal progress towards wisdom. As Roskham (2005) articulates clearly, for Epictetus moral progress is an internalized process:

motivate action. Also if these exercises do not teach us new beliefs, but only help us digest theory we already have, then what does this digestion look like on a psychological level? How can the "soul be transformed" if this does not refer to the introduction of new beliefs? Such a picture requires much additional justification to save itself from threats of incoherence. 
Epictetus' position [on wisdom being sufficient for virtue] leads to a complete interiorization of the whole process of moral progress. The road towards perfection lies in

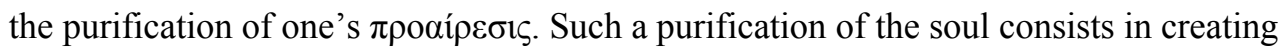
within it proper judgements, and will result in the removal or abatement of many negative characteristics...The more frequently one shows a proper judgement or attitude, the more progress one has made. (116)

So for Epictetus, proper external actions are only indicative of progress because they are motivated by internal judgements and attitudes. It is these internal beliefs that are where the real moral progress occurs. So if digestion is essential to moral progress, then it has to impact our beliefs. The problem that becomes apparent is that, according to Sellers, theory is supposed to be the part of Epictetus' educational program that takes care of creating proper beliefs, judgements and attitudes. I suspect the reason Sellers argues that digestion is concerned with modifying external actions is that this gives spiritual exercises a unique role different from that of theory. If spiritual exercises are directed towards modifying belief then it becomes vague as to how exactly they differ from theory, and it becomes unclear why Epictetus placed such an emphasis on them. This is why Sellers wants to create a role for spiritual exercises that is distinct from that of theory.

However, the unique role that Sellers has prescribed is simply untenable given the commitments Epictetus has to an internalized conception of moral progress. For Epictetus moral progress must, in some form, involve the modification of belief.

My aim for the rest of this thesis is to take some of the insights raised by Sellers, and apply them to the problem brought forward by Brennan, while resisting the stronger 
claims of Cooper. My goal is to construct an interpretation of spiritual exercises in Epictetus that has three conditions:

A) They involve in some way the modification of beliefs and are thus a part of moral progress;

B) The way they modify beliefs is different from studying theory. Thus these exercises are necessary for moral progress since they provide something that theory does not;

C) They do not modify belief through non-rational means. Thus they do not conflict with intellectualism. 


\section{Chapter: Spiritual Exercises Reimagined}

In the first section of this chapter I define and defend my own interpretation of the role of spiritual exercises in Epictetus that meets the three criteria I provided at the conclusion of Chapter 2. This interpretation is that the role of spiritual exercises, just like theory, is the modification of belief through rational means, but the type of beliefs addressed by spiritual exercises are necessarily distinct from those of theory. I will argue that theory is focused on modifying general, overarching beliefs, whereas spiritual exercises help us modify specific beliefs about individual contexts and situations. In the next two sections I will examine a paper by Braicovich (2012) in which he provides an interpretation of one specific spiritual exercise, which he calls "repetition". I will argue that Braicovich's interpretation of the "repetition" exercise is perfectly in line with my own theory about the role of spiritual exercises in Epictetus, and as such it provides a succinct example of how my theory could be applied to a particular exercise in Epictetus. More so, Braicovich's explanation of the "repetition" exercise is worth going over in detail as it relies heavily upon the concepts of critical assent and belief subsets. These concepts will be essential in Chapter 4 for my own interpretations of the role of the two exercises that I will call the Habituation Exercise and the Questioning Exercise.

\subsection{Spiritual Exercises and Specific Beliefs}

In the previous section I concluded by defining three criteria that must be met in order for an interpretation of Spiritual Exercises to be coherent with the philosophy of Epictetus. I outlined the interpretations of Cooper and Sellers, as well as discussed a 
prominent problem raised by Brennan. In this section my goal is to outline my position, but I will not defend it yet. The interpretation I propose will be very similar to that of Sellers, but I define the process of digestion differently. The remainder of this thesis will be dedicated to defending such an interpretation through examples of how spiritual exercises are employed within the Discourses, and an examination of the metaphors that Epictetus uses to describe them.

I agree with Sellers that spiritual exercises are the second half of a two part program, which also includes theory. I agree that Epictetus deemed both theory and these exercises to be essential for moral progress, and that these exercises must follow theory, because they presuppose the students grasp of Stoic precepts and logic. I also agree that the aim of these exercises was to allow for the "digestion" of theory. My conception breaks from Sellers in terms of what this digestion entails. For Sellers, digestion refers to a process through which theory becomes manifested in our actions. It is the process by which we begin to act in accordance with theory. I think that this is a by-product of digestion, but not what makes it valuable or essential for progress. I will argue instead that it is better to interpret Epictetus as meaning that digestion is the forming of specific beliefs, rather than general beliefs, that are in accordance with Stoic theory. Thus the purpose of spiritual exercises is to cause digestion, or in other words to maximize the formation of correct specific beliefs that are in accordance with the theory.

Before I proceed any further, I need to clarify some terminology. What I mean by specific beliefs are beliefs that have a certain object they are directed toward. I am contrasting this with general beliefs, which have no specific object of focus. So for example, a specific belief would be "my mother has intrinsic value", one's mother being 
the specific object of that belief. A general belief would be "mothers have intrinsic value", since "mothers" refers to no specific object, but rather a kind of form, namely the form of "mother" in general.

Studying theory consists of getting students to understand, and assent to, general beliefs. Precepts are always general in form: "Externals are indifferent", "The only thing that matters is what is up to us" etc. Ideally, assenting to a general belief entails automatically assenting to all of its specific forms. For example, if I assent to the precept “externals are indifferent", then this would hopefully cause one to assent to the specific beliefs "my car is indifferent" or "my mother is indifferent". However, the Stoics concede that all but the sage are very ignorant. We hold many false beliefs and are also biased by our own perspective. By the time we reach adulthood we have already assented to many false specific beliefs, and these beliefs are stubborn and deeply ingrained within us. What happens because of this is that students are able to learn a precept in the classroom, and genuinely assent to it and genuinely understand its truth, but when they try to apply that theory to their own lives, it is rejected as false since it contradicts so many beliefs they already hold. For example, a student may quickly assent that "the only thing that matters is what is up to us" when talking to the teacher, but in the presence of her own family or child, the student recalls all the specific beliefs she has about their value and worth to her, and the incredible number and strength of these false specific beliefs cause her to ignore the precept.

This, I argue, is the process Epictetus describes when he talks of vomiting up precepts. "Those who have learned precepts as mere theory want to vomit them up immediately, just as people with weak stomachs do with their food. Digest your precepts 
first, and you will not vomit them up in this way; otherwise they really do turn to vomit, tainted matter unfit to eat" (3.21.1-2). Precepts often seem repulsive to us when we learn them as "mere theory" because, even if we assent to them on a general level, they still contradict so many of our specific beliefs. We will vomit up our precepts when confronted by a particular situation that evokes our false beliefs. So in order to avoid this we must digest our theory. But digestion cannot entail just more "mere theory": as Sellers acknowledged this is clearly insufficient to Epictetus, so we must also incorporate spiritual exercises. It is these spiritual exercises, not theory, which have the role of helping the student assent to correct specific beliefs.

The reason spiritual exercises motivate us to form specific beliefs, whereas theory cannot, is that these exercises are all decidedly specific in nature. They are all supposed to be employed when the student is out in the world, interacting with specific people and specific objects. Theory is necessarily general. It is learnt in the classroom, and does not require interaction with other people or events to learn.

The nature of spiritual exercises to be directed towards specific events is, I believe, why Sellers argues that they are focused towards changing our actions. But, as I argued in Section 2.3, modifying our actions is not essential, or even necessary for moral progress. What is necessary is changing our beliefs. These beliefs will then have the unessential by-product of changing our external actions, but these actions only represent progress, they are not the actual progress. For example, what displays a student's progress is not his 'Stoic' appearance at a funeral. What displays progress is the specific belief that motivates that behaviour. And that belief is not valuable because it motivates the behaviour; it is valuable in and of itself. Wisdom is virtue. 
There is no doubt that for Epictetus correct specific beliefs have intrinsic value. And they would also have instrumental value, but not when it comes to motivating our actions as Sellers would argue. Rather, these specific beliefs are instrumentally valuable because they, in combination with theory, allow us to assent to other, more challenging specific beliefs. For example, imagine I cherish my car above all else. Without training I may be unable to assent to the impression that "my fancy sports car has no intrinsic value". I will have too many specific beliefs to the contrary, such that I vomit up my theory when I try to assent to such an impression. But through training, I will assent to less extreme specific beliefs that support Stoic theory. I can gain specific beliefs such as "my bicycle has no intrinsic value" or "my friend's sports car has no intrinsic value". These are more easily assented to, since I do not value them as highly. However, when I have formed enough of these beliefs, they then provide the evidence required to make me reject my previous false belief about the value of my own car, and form a new belief that is in line with Stoic theory. I can assent to "my fancy sports car has no intrinsic value" because my general beliefs, as well as my other specific beliefs, support such a conclusion.

And this is then what it means to digest a theory. If a theory is digested, it means that all my specific beliefs are in accordance with that theory. The more digested a theory is, the more my beliefs are in line with it. Also a digested theory will not be rejected or "vomited" because I have no beliefs to contradict it. Finally, this will be reflected in my actions, because it is these specific beliefs that motivate my actions. It is the specific belief that "my mother's death is indifferent" that will motivate me not to grieve, not the general belief that "externals are indifferent". 
A benefit of this interpretation is that we also get a conception of moral progress that progresses incrementally and thus may really be called progress. From such a conception, we have a reason why Epictetus thinks we must start with smaller problems before we move onto bigger ones. We have an understanding why Epictetus describes our knowledge of theory in a way which seems to become stronger or weaker depending on our choices. Even though we possess an unimpeded rational faculty, the reason we cannot immediately assent to all true impressions is because we are too ignorant. This ignorance must be done away one specific belief at a time, through vigorous training in spiritual exercises.

So returning to the three criteria a spiritual exercise must have, this interpretation meets all three.

A) Spiritual exercises involve in some way the modification of beliefs and are thus a part of moral progress:

I have argued that the true specific beliefs gained through spiritual exercises are both intrinsically good in and of themselves, and instrumentally good, in that they provide evidence to assent to other true specific beliefs. These exercises are essential for moral progress because without the beliefs they cause there are certain impressions we will be unable to assent to with theory alone.

B) The way spiritual exercises modify beliefs is different from studying theory. Thus these exercises are necessary for moral progress since they provide something that theory does not: 
Spiritual exercises are concerned with the specific in a way that theory cannot be. Theory must be general. Thus there is a certain type of progress, described as digestion, which can only be achieved by spiritual exercises. Theory cannot digest theory.

C) Spiritual exercises do not modify belief through non-rational means. Thus they do not conflict with intellectualism:

Under my interpretation, Epictetus conceives of spiritual exercises as helping with the formation and modification of specific beliefs, but they in no way insert themselves upon or alter the rational process by which beliefs are modified. These exercises are never a non-cognitive force that acts to compel the mind in the place of rational evidence. Instead they aim to stack the evidence in favor of the truth, by providing more abundant and readily available specific beliefs. These true specific beliefs are then the evidence that causes the Stoic to modify their belief in accordance with the truth of the matter. Thus, spiritual exercises modify belief in just as rational a means as theory or argumentation does.

At this point, I will turn from discussing spiritual exercises in general to discussing specific spiritual exercises. Each of the three exercises I will discuss, the Repetition Exercise, the Habituation Exercise, and the Questioning Exercise, have a specific role to play in maximizing the formation of correct specific beliefs. All three exercises cause digestion of theory by helping the student to form proper specific beliefs, but they each do so in a unique way. I will argue that each exercise does the following: 
1) Repetition Exercise: Ensures that correct theory and precepts are available to us during critical assent ${ }^{19}$.

2) Habituation Exercise: A) Causes the formation of correct specific beliefs and B) ensures that correct specific beliefs are available to us during critical assent.

3) Questioning Exercise: Supports the other two exercises by ensuring that critical assent occurs.

I have argued in this section that the role of spiritual exercise is to help with the formation of correct specific beliefs. This formation takes place at the moment of assent, or lack thereof if the impression seems false. Thus all three of these exercises are designed to help ensure that our assent is as successful as possible when confronting impressions about specific objects. ${ }^{20}$ By successful I mean corresponding to the truth of the matter. An assent that yields an untrue belief would be unsuccessful. As such, all three exercises have a different role to play within that process, but their aim is identical. They all aim at ensuring that one's assent, when confronted with impressions about specific objects, corresponds to the truth. This leads to a digestion of theory, as our beliefs about specific objects begin to align with the theory we have already learnt. When

\footnotetext{
${ }^{19}$ I have not introduced the concept of critical assent yet, but it is the subject of the next chapter.

${ }^{20}$ Presumably the reason why we do not require such help when assenting to precepts and theory is because of our inherently rational nature. Rational forms of argument are sufficient to have us see the truth of the matter when it comes to general objects, but specific objects are more difficult, due to our ignorance. Thus we must try and stack the odds in our favor by employing these exercises.
} 
understood in such a way, these exercises are wholly compatible with intellectualism, and the worries of Brennan disappear.

In the next two sections I examine a paper by Braicovich (2012), where he attempts to save the Repetition Exercise from the claims of incoherence raised by Brennan. Braicovich argues that the purpose of the Repetition Exercise is just as I have described in 1). Additionally, by introducing the concepts of critical assent and belief subsets, Braicovich also lays the foundation for how I will interpret the other two exercises in the next chapter.

\subsection{Critical Assent:}

Braicovich's 2012 paper "Critical Assent, Intellectualism, and Repetition in Epictetus" was inspired by Brennan's concerns about the apparent conflict between spiritual exercises and intellectualism. Within the paper, Braicovich attempts to preserve the coherence of one particular spiritual exercise, which he calls "repetition".

Braicovich's goal is to show that the Repetition Exercise (RE) ${ }^{21}$, despite being a spiritual exercise, has a coherent role within the framework of Epictetus' intellectualism. He does this in a way similar to what I have argued in the previous section. He argues that RE is not meant to modify beliefs through non-rational means, but rather to help ensure that our critical assent is successful. However, Braicovich's aim is different from my aim in that

${ }^{21}$ The Repetition Exercise will be referred to as RE from this point on to avoid confusion with other forms of repetition in Epictetus. I do not agree that "repetition" is the best name for the exercise, since it is neither referred to explicitly by Epictetus as such, nor is it the only example of repetition in Epictetus, but I will keep it to be faithful to Braicovich's text. 
he is concerned only with preserving one specific exercise. He does not extrapolate his argument to other exercises, or attempt to propose that there may be a common goal or role for all of these exercises that is compatible with intellectualism.

Braicovich also makes a great contribution towards understanding spiritual exercises by recognizing the importance of critical assent in Epictetus and its relation to spiritual exercises. Once we understand the importance of critical assent in Epictetus' moral therapy, we can then understand how and why spiritual exercises allow for the formation of proper specific beliefs in a way that theory alone cannot.

Before proceeding it is important to clarify what critical assent is. Critical assent is where we create an extra step in the process of assenting to impressions. It is where withholding from assent becomes the default state, so that we do not mistakenly give our assent to the wrong impressions. This is to be contrasted with precipitate assent, which is spontaneous. Braicovich describes critical assent as "the act of refraining from assenting" to incoming impressions that seem true or false (318). Since our default state is to immediately assent to that which seems true, and dissent from that which seems false, critical assent "will be the result of a practical decision, [it is] an act which, far from being natural and spontaneous, will probably demand a great deal of effort and training" (318). In other words, critical assent does not come to us naturally. It must be worked at and practiced. We must make a conscious effort to train ourselves to prevent precipitate assent and only perform critical assent. Exactly how this should be practiced will be discussed in Chapter 4.

At first, performing critical assent may seem to be in conflict with Epictetan psychology. Through what cognitive means can we withhold assent, if our mind cannot 
help assenting to that which seems true? We must recall that the rational faculty has three possible reactions when it comes to impressions. It must assent to what seems true, dissent from what seems false, and suspend judgement on what seems to not be immediately knowable (1.28.1-5). Suspending judgement is a natural process of the mind for Epictetus, it is just that the untrained person does not employ it nearly enough, since they are carried away by the strength of any impression or fooled by the perceived reliability of their intuitions about value. Thus, when we become aware and purposeful with the use of our rational faculty, withholding assent will be as natural a process as giving assent was in the first place.

Epictetus confirms the importance of critical assent throughout the Discourses:

For, just as Socrates used to say that we are not to lead an unexamined life, so neither are we to accept an unexamined impression, but to say, 'Stop, let me see what you are, and where you come from', just as the night-watch say, 'Show me your token.' 'Have you that token from nature, which every impression must have if it is to be accepted? (3.12.15)

The first and greatest task of a philosopher is to put impressions to the test and distinguish between them, and not admit any that has not been tested. (1.20.7)

I will show you the sinews of a philosopher.

What sinews are those?

Desire that never fails in its achievement; aversion that never meets with what it would avoid; appropriate impulse; carefully considered purpose; and assent that is never precipitate. (2.8.29) 
The importance of critical assent is clear. As already established, the objective of Epictetus' moral therapy is to hold correct beliefs. For him, this is sufficient for being virtuous and happy. But the process of achieving virtue is not as simple as teaching a student lessons. Imagine what would happen if one was to say to a regular person any of the following: 'you have no control over what happens outside of your realm of choice', 'your family is dead and this is indifferent', 'it does not matter if you are chained in a jail alone, or well-fed in your own home surrounded by your best friends, in both cases you can be just as happy'. Nobody would assent to any of these as true. They may even become angry or offended, confident that just the opposite is true. If these statements are true, and humans necessarily assent to what seems to be true, then why do we not assent to these statements? It must be because they seem to be false. And they seem to be false because of our current set of beliefs. This is the feedback loop of belief modification discussed in Section 1.4. Someone who has a lot of beliefs about the inherent value of their families is going to have a much harder time believing their families death to be morally indifferent than someone with comparatively lukewarm judgements towards their family.

In other words, forming new beliefs is never done in a vacuum. We carry our baggage with us. We bring along all our false and correct beliefs, and these play a crucial role in determining if we are able to assent to true impressions. It is these beliefs that determine if impressions strike us as being true or false. As such, it is crucial for the sake of moral progress to be incredibly cautious about giving our assent to an impression. Each new belief that we form will either contribute towards the future forming of correct 
beliefs, or lead us towards ignorance and impede our ability to assent to that which is true. Thus in order to be a good stoic, we must practice critical assent. Being a stoic demands "a complete alertness concerning our impressions, and that we be constantly on guard against every impression that comes to us, systematically distrusting what they pretend to ascertain of the world around us" (Braicovich, 321).

However, critical assent is only useful for our progress if it leads to the forming of more correct beliefs than precipitate assent would. It might be a necessary condition of virtuous belief formation, but it is not a sufficient condition (Braicovich, 333). If I withhold assent to scrutinize an impression, only to then assent to something false, I am no better off than I was before if I had given precipitate assent. Epictetus thus needs to ensure that when practicing critical assent we only assent to impressions that are true. According to Braicovich this is where repetition comes in.

\subsection{Repetition Exercise}

As I mentioned previously, in his paper Braicovich only addresses a specific kind of spiritual exercise in Epictetus. This is the RE, or Epictetus' constant reminder for us to be mindful of Stoic principles and to repeat them to ourselves. RE is a predominant theme in the Discourses. Throughout his work, Epictetus demands that we perpetually have the proper beliefs ready at hand, or accessible to us, through the constant mental repetition of those beliefs. Braicovich cites the following examples from the Discourses:

If you send me to a place where men cannot live in accordance with nature, I shall depart from this life, not out of disobedience to you, but in the belief that you are sounding the signal for my retreat. I do not desert you; heaven forbid! But I perceive that you no longer 
have need of me. If a life in accordance with nature be granted, I will seek no other place but that in which I am, nor any other company but those with who I am'.

Have these reflections at hand by night and day. Write them down, read them, talk about them, both to yourself and to somebody else when you say, 'Is there any help that you can give me in this?' And then approach another man and then another. Then, if any of those things that are called undesirable should happen, it will, in the first place, be an immediate relief to you that it was not unexpected. (3.24.101-104)

Having these thoughts always at hand, and engrossing yourself in them when you are by yourself, and making them ready for use, you will never need any one to comfort and strengthen you. (3.24.115)

In these passages, Epictetus is encouraging us to have proper beliefs constantly "at hand" and "ready for use". For Epictetus, the kind of proper beliefs that need repeating all derive from the crucial distinction between what is up to us and what is not. Epictetus provides the following example of how to properly approach oncoming impressions while also reminding ourselves the important distinction between what is up to us and what is not:

'So -and-so's son is dead. What do you think of that?' It lies outside the sphere of choice, it is not an evil. - 'So-and-so has been disinherited by his father. What do you think of that?' It lies outside the sphere of choice, it is not an evil. - 'Caesar has condemned him.' - This lies outside the sphere of choice, it is not an evil. - He has been distressed by this. - This is within the sphere of choice, it is an evil. - He has borne it nobly. - This is within the sphere of choice, it is a good. (3.8.1-3) 
With each impression Epictetus reminds himself that all that matters here, all that is essential, is whether what occurred is within or outside of the sphere of choice. And if we keep that in mind we will arrive at the correct judgement about whether the impression is an example of a good, an evil, or something indifferent. As such, if we keep these beliefs in mind by repeating them to ourselves, we shall find "immediate relief" and not need external comfort when faced with impressions that would otherwise be considered undesirable or painful to us. At first this seems intuitively non-cognitive. Why is repeating doctrine necessary if I already know it to be true? And if I do not consider it to be true, how can repeating it ever help me?

Braicovich goes on to explain that if we understand the importance of critical assent then RE clearly has a very coherent role within Epictetus' intellectualism. Recall that belief formation is when an impression is cross-examined against current beliefs, and either found to be consistent and true, or contradictory and false. Critical assent is where this process of belief formation becomes intentional. It becomes something that we participate in with mindfulness, rather than something that we do passively, or without our active vigilance. Thus, if we are practicing critical assent, then during belief formation we are consciously comparing a new impression with our beliefs.

But it is not reasonable, or even possible, to compare an impression to all our beliefs. We can only compare an impression to a relatively small number of our total beliefs. As such, the quality of our assent is determined by the quality of the beliefs we compare the impression to. Braicovich argues this point: 
Epictetus knows that the act of examining an impression cannot possibly consist of a logical confrontation against the totality of our beliefs and opinions, but rather that the beliefs, the ideas against which the confrontation can take place, are merely a subset of that totality, which is why it becomes all the more pressing to make sure that the correct (and relevant) beliefs be at hand when it is time to deal with any given impression. (Braicovich, 332)

Before going any further, it is worth discussing the concept of a subset of our total beliefs in further detail than Braicovich goes into. I will refer to this subset of our total beliefs as our belief subset from here on. A belief subset refers to the beliefs that are compared with an incoming impression. The Stoics would agree that we have an enormous number of beliefs. Some beliefs are conscious to us, such as whatever happens to currently hold my focus and attention. Some beliefs are not conscious currently but could be if we try to remember them, or if an impression evokes them. For example, I am not always conscious of my belief that elephants are large land mammals, but it is most certainly present; If asked, I would readily agree without the need to deliberate. Some beliefs are inaccessible without stringent vigilance and self-examination, such as perhaps certain complex beliefs about our past experiences or our relationships with loved ones.

According to the Stoic view, when I am confronted with a new impression I will compare that impression to my current beliefs. But I do not compare that impression to all my beliefs in total. For example I do not compare my impression about an elephant to my beliefs about Mexican food. This is both unnecessary and unrealistic. Rather I compare the impression to beliefs concerning the object of that impression. So I compare my impression of an elephant to my beliefs about elephants, mammals, animals in 
general etc. I also compare my impression to beliefs that are conscious to me at the time. These are the beliefs that are "on hand", and readily accessible. As Braicovich warns, these "on hand" beliefs may not always be correct, or even relevant. This is my belief subset. It is comprised of beliefs concerning the object of the impression and beliefs that I am currently conscious of; it is what I have "on hand".

If one's mind has "on hand" false beliefs, then these false beliefs form a large part of the subset with which one compares the incoming impression. In such a case one is much more likely to assent to a false impression. This makes intuitive sense, even on the non-stoic picture. ${ }^{22}$ If I am constantly reminding myself of how awful death is, then I am more likely to think "that is horrible!" when I hear of a friend's death. The opposite can be said if my mind is filled with correct Stoic precepts. If I am constantly reminding myself that "the only thing that is good or bad is what is up to us", then I am more likely to recognize death as indifferent. If my mind is filled with precepts, then these are the beliefs that I will compare incoming impressions to. In such a state, one is much more likely to only assent to true impressions. Therefore the state of one's belief subset becomes very important to ensure virtuous or good belief formation. We see this process in action in the following passage:

${ }^{22}$ For example, it is common sense that it would not be a good idea to read stories about horrific plane accidents immediately before flying. Even though we should know, in spite of these stories, that statistically flying is a comparatively safe form of travel, these kinds of stories can dispose us to interpret normal turbulence as something dangerous and thus cause unnecessary stress. 
If you set these thoughts against your impression, you will overpower it, and not be swept away by it. But in the first place, do not allow yourself to be carried away by its intensity: but say, 'Impression, wait for me a little. Let me see what you are, and what you represent. Let me test you.' Then afterwards, do not allow it to draw you on by picturing what may come next, for if you do, it will lead you wherever it pleases. But rather, you should introduce some fair and noble impression to replace it, and banish this base and sordid one. (Discourses, 2.18.24-26)

In order to not be swept away by an impression, Epictetus encourages us to withhold assent even though it seems true. This is the practice of critical assent. This pause gives me time to compare the impression to a specific belief subset. If that subset has a "fair and noble impression" you may assent to that one instead and be saved from forming a false belief. However, we can see that if we have no "fair and noble" impression to introduce, then we will not be able to replace the base and sordid one. Consider this famous passage from The Handbook: "In the case of everything that delights the mind, or is useful, or is loved with fond affection, remember to tell yourself what sort of thing it is...If you kiss your child, or your wife, say to yourself that it is a human being that you are kissing; and then you will not be disturbed if either of them dies" (Handbook, 3).

By constantly repeating that your wife and child are mortal, and properly understanding the potential of death that is entailed by this mortality, then you have primed your belief subset with true beliefs about them. And thus in the case of death you will not form false beliefs, and you will not be disturbed. You will not assent to the base and sordid impression that their death is somehow unexpected or against their nature and 
thus a great grievance to you. While this may seem like an extreme achievement for anyone but the stoic sage, if the regular student practices the RE then at the very least they are maximizing their chances to not be disturbed, and helping to minimizing the pain and duration of that disturbance if it does occur.

Thus the cognitive role that RE performs is to prime this subset of our beliefs. By repeating Stoic lessons I ensure that my belief subset contains many true general beliefs. More importantly, it ensures that my subset contains significant general beliefs about what is important, like the indifference of externals, the mortality of my family, or the inherent worth of a life lived in accordance with nature. These are the kinds of beliefs that may be called fair and noble when they are brought to mind. Having these beliefs on hand in my belief subset maximizes my chances of correct belief formation, because it is more likely that a true impression will seem true, and a false impression will seem false.

Braicovich thus concludes that it is clear that the RE has a wholly cognitive role. The RE does not stand in conflict with Epictetus' intellectualism because the RE does not non-rationally modify our belief, and the repetition involved plays no direct evidential role.

The reason why Epictetus' techniques of repetition do not stand in contradiction with his intellectualist approach to human action is that the goal of those techniques is not that the individual may see the truth of a certain impression, but rather that certain ideas (i.e., impressions which have been assented to and have thus become dogmata) be at hand, ready and available to become the background against which each new impression is to be tested. (Braicovich, 332) 
In other words, Epictetus does not intend for constantly repeating and remembering doctrine to help us non-cognitively overpower current false beliefs, or persuade us to see the falsity of something that we already assented to. This is to mistakenly assume RE is directed towards non-rational belief modification. Instead, the exercise is actually designed to coincide with critical assent, and allow a higher quality belief subset. Understood in this way any potential problem dissolves. This belief subset, and the new beliefs that are formed as a result of it, will provide evidence for modifying old beliefs, not the repetition itself. ${ }^{23}$

This interpretation also coincides with Sellers' (2007) argument that spiritual exercises must follow after theory. While Braicovich is not explicit about this point, it is clear from his explanation that he sees the goal of RE as helping to ensure the success of

${ }^{23}$ It is worth clarifying here the similarities between what Braicovich calls the "belief subset" and the Stoic Chrysippus' talk of oscillating beliefs. I think the two concepts are wholly compatible, and just two separate ways of approaching the same occurrence. Roughly speaking, Chrysippus describes different beliefs as oscillating rather than conflicting with one another. For example, if someone I cared for has died many years before, a memory of them might evoke either acceptance or grief depending on the day. One moment I will see an object that reminds me of my loved one, and this will cause a pleasant appreciation for them, and later that same day they may see that same object and it will cause a reaction of grief. Chrysippus would not say that grief (which is rooted in false beliefs under the Stoic picture) and acceptance are simultaneously battling it out within my divided soul. Rather at one moment I really accept that loved one's passing with my whole being, and in another different moment I am just as totally convinced of how terrible their absence is. Belief subsets provide a perfect explanation of how this could happen. If my belief subset is composed of virtuous ideas, then their memory will evoke a calm acceptance. But if my belief subset consists of false ideas (perhaps the belief that I no longer have access to a happy life now that they are gone), then their memory will evoke beliefs and judgements that cause grief. A benefit of practicing the $\mathrm{RE}$ then is that I will never oscillate towards grief, because I will never allow my belief subset to become full of false beliefs. See Nussbaum (Therapy, 383-386; Upheavals, 8687) and Gill (1983) for excellent descriptions of Chrysippus' theory. 
critical assent when it comes to impressions about specific objects. RE, as described by Braicovich, is not intended to help us learn theory, because RE requires that we already know the theory. It is only possible to practice RE if we already have the correct beliefs derived from theory, because these are what we repeat to ourselves.

To review, by practicing RE we are more likely to form correct beliefs about specific objects because we ensure a higher quality belief subset during critical assent. For Epictetus, RE is not theory; it is not something we practice in the classroom. It is something we practice when we are out in the world, interacting with unique people and situations. If we do not practice RE, that is, if we do not repeat Stoic precepts to ourselves, then we run a higher risk of forming false specific beliefs about the impressions one is constantly confronting. In this way RE is not a tool for assenting to theory we do not agree with, but rather a tool for digesting theory that we already endorse. RE better allows us to form specific beliefs in accordance with that theory by ensuring that the theory is always conscious and present to us, and never forgotten.

It should be evident by this point that Braicovich's interpretation of RE is wholly compatible with the role of spiritual exercises that I have proposed. Recall from earlier in the chapter the proposed purpose of the RE:

Repetition Exercise: Ensures that correct theory and precepts are available to us during critical assent.

While Braicovich's explanation of this particular exercise is excellent, there is still work to be done. Braicovich only addresses one spiritual exercise, the RE. As we have 
seen, this is Epictetus' constant reminder for us to repeat to ourselves certain precepts to have these thoughts constantly ready at hand and accessible. These precepts include that the only thing up to us is the employment of our rational faculty, and that anything that is not up to us cannot be an evil or a good. While this is a spiritual exercise, it does not encapsulate all the different forms of spiritual exercises employed by Epictetus. There are at least two other spiritual exercises employed by Epictetus, the Habituation Exercise and the Questioning Exercise. ${ }^{24}$ Since Braicovich's paper was focused on RE in particular, we require an explanation of how these other exercises fit within intellectualism, and how they contribute to the formation of proper specific beliefs.

In the following two chapters I address the two other types of spiritual exercises in Epictetus, and demonstrate that they also are directed towards the formation of proper specific beliefs. My proposed explanations are strongly linked to Braicovich's. Going through Braicovich's paper in such great detail was necessary because of the emphasis he places upon the role of critical assent and belief subsets. Much like for RE, critical assent and belief subsets hold a crucial role in explaining how these exercises are not intended to non-rationally modify beliefs. Rather, they are intended to help in the formation of true specific beliefs.

\footnotetext{
${ }^{24}$ There are probably more exercises employed by Epictetus which would warrant further research, but I am confident that these three are the ones most prominently utilized, and within the scope of this paper exploring them will be sufficient to demonstrate my argument.
} 


\section{Chapter: Habituation Exercise and Questioning Exercise}

In this chapter I take the conception of spiritual exercises that I established in Section 3.1 and demonstrate how the two other spiritual exercises in Epictetus, the Habituation Exercise (HE) and the Questioning Exercise (QE), fit perfectly within this framework. In doing so, I aim to demonstrate that all of Epictetus' spiritual exercises are aimed at helping the formation of correct specific beliefs through rational means. My aim is to save spiritual exercises as a whole from the threats of incoherence raised by Brennan, while still respecting their necessary and unique role in our moral progress.

\subsection{Habituation Exercise Described}

The first exercise I examine is the Habituation Exercise. I will refer to this as HE, to differentiate it from habituation as a concept removed from the specific exercise. Habituation in general is a process which relies upon repetition. It is a process by which something becomes normalized through repeated exposure or performance. As such, something can only be called a habit if it is done repeatedly. ${ }^{25}$ One may have a certain innate tendency or inclination towards certain behaviour, for example I may have the inclination to get angry easily, or to really enjoy gambling. But these inclinations cannot be said to be habits. One does not have a habit of getting angry or gambling unless one

\footnotetext{
${ }^{25}$ Although repetition is necessary for something to be a habit, it is not sufficient. Something done repeatedly is not always a habit. In order for something to become a habit there must be an internalization of the behaviour, or a change in the self that perpetuates that behaviour in the future. As we shall see shortly, for the Stoics this change must be in our beliefs.
} 
actually gets angry or gambles. And even then, this action must be performed repeatedly before it can take the shape of a habit.

There is no doubt that there is something that seems intuitively non-cognitive in the way we talk about habits. Perhaps this is because 'bad' habits are constantly referenced as something that makes us act against our better judgement. We know that we should not gamble and it does not make rational sense to purchase a lottery ticket even if we value wealth, but we do anyway because it is a habit. We talk about this habit as if it overpowers one's better judgement, and compels them to act irrationally. 'Good' habits seem to have the same non-cognitive persuasive force. One may not want to eat a healthy meal, or abstain from drinking, or go for a run, but there is no doubt that if one has become habituated to such behaviour through years of training then they are more likely to successfully complete the task than someone who has not made a habit of it. A good habit allows us to do what we should do, instead of succumbing to the irrational desire to do what we feel like doing at a particular time. Likewise a bad habit impedes us from doing what we should do, even when we know it is wrong. At least this is the way we commonly talk about habits colloquially. Such a picture cannot possibly fit with Epictetan intellectualism.

However, Epictetus does not disregard the concept of habits as one might assume. Nor does he acknowledge habits as only a problem for people who attach desires to objects outside of their control. Rather he acknowledges the necessity of cultivating proper habits if we want to become virtuous. Habituation of proper external behaviour is 
a significant spiritual exercise for Epictetus. ${ }^{26}$ Throughout the Discourses Epictetus

makes various references to the necessary role that performing good habits, and

abstaining from bad habits, will play in our moral therapy:

If it is a habit that afflicts us, we must endeavour to discover aid against that.

What aid, then, is it possible to discover against habit? The contrary habit. You hear people say, 'Poor soul, he is dead; his father died, his mother died, he was cut off before his time and in a foreign land.' Listen to the contrary arguments, draw away from these expressions. Oppose to one habit the contrary habit; to sophistic arguments, the art of reasoning, and the frequent use and exercise of it. Against specious appearances we must have clear preconceptions, polished and ready for use. (1.27.3-6)

For, without severe and constant training, it is not possible to ensure that our desire should not fail or our aversion should not fall into what it would avoid: so you should know that if you allow your training to be directed towards external things that lie outside the sphere of choice, your desire will neither gain its object, nor your aversion avoid it.

And because habit has a powerful influence, when we have become habituated to apply our desire and aversion to externals only, we must oppose one habit to another, and where impressions are most liable to make us slip, there resort to training to counter the risk. I am inclined to pleasure. I will move to the opposite side of the deck to a greater extent than usual for the sake of training. I have an aversion to suffering. I will train and exercise my impressions to ensure that my aversion is withdrawn from everything of this kind. (3.12.5-7)

\footnotetext{
${ }^{26}$ For an excellent general outline of habituation in Epictetus see Stephens (2013).
} 
There is a lot of information about how Epictetus conceives of habits and their role in moral therapy that can be taken from these passages. First, we see that opposing habits are in a necessary conflict with one another. This seems intuitive. I cannot both have the habit of smoking, and the habit of not smoking. As such, the way to defeat a bad habit is to foster and make stronger "the contrary habit". Likewise, the best way to destroy a good habit is to repeatedly give myself up to a bad habit.

Second, Epictetus seems to believe that there are different types of habits. While presumably all habits can ultimately be simplified to an archetype form, the good habit of making good use of impressions and the bad habit of making bad use of impressions, this is not the best way to conceive of them if we wish to ensure progress for a Stoic in training. Rather, we should conceive of habits as also being individual and unique to the specific contexts. In other words, unique situations contain unique good and bad habits. In these two passages we see that there are the habits of succumbing to sophistical arguments, being fooled by specious appearances, being inclined towards pleasure, and being averse to suffering. Each and every one of these bad habits will have a contrary good habit that matches their respective form. This is to say that proper habituation is not as simple as trying to counter one's habit of being inclined towards pleasure with the habit of making good use of impressions. While making good use of our impressions is the ultimate goal, to practice this will not be effective here because it does not correspond to the specific nature of the bad habit we are trying to correct. The contrary good habit to a bad habit must be as specific as that bad habit is. Thus one must foster the contrary habit of not being inclined towards pleasure, in order to dispel habit of being inclined towards pleasure. 
Third, Epictetus encourages us to focus our training on "where impressions are most liable to make us slip". This means that training should be disproportionately focused on our most ingrained bad habits. The worse a habit, and the more often it is indulged, the more work it will take to replace it with a good one. Thus I should not cultivate aim to all good habits equally. To make the best use of one's time, one should focus primarily on developing good habits that counter our most frequently indulged bad habits. This seems intuitive, even for a non-stoic. If my most prevalent emotion is anger, and I constantly indulge this habit and lash out in inappropriate ways, then my time is best spent working on staying calm and cultivating a habit of serenity and peace. If I spent time focusing on habits that were not as detrimental to my character, I would be avoiding the real issue.

While Epictetus' advice seems reasonable from a non-stoic perspective, when we consider his commitments to intellectualism, Brennan's worries emerge again. Any exercise involving habituation as a form of moral therapy just does not seem intuitively compatible with a wholly rational mind. As stated earlier, repetition alone gives us no additional rational reasons to believe or not believe something. This is the same for repeating doctrine in the RE, but also in repeating external actions. It seems that by performing acts that lead to good habits consistently, I give myself no new rational reason to believe that this action is correct or worth doing.

Thus if I already believe an action is good, under the intellectualist picture this knowledge will be sufficient to motivate my behaviour. If I do not believe it is good, then it is unclear how repeatedly forcing myself to perform it will give me a reason to believe otherwise. The worry is that practicing the habituation of good actions is giving us some kind of necessary non-cognitive reason or motivation to perform proper actions. This 
would contradict intellectualism because, as discussed in Section 2.1, it would be an example of non-cognitive belief modification.

\subsection{Habituation and Specific Beliefs}

My goal for this section is to show that the Habituation Exercise (HE) is not aimed at non-rational belief modification, but rather at helping to form correct specific beliefs. Demonstrating this will also show it to be coherent with intellectualism. More specifically, I argue that the HE, unlike the other two exercises, has two purposes for Epictetus. First, it causes the formation of correct specific beliefs, and is thus intrinsically valuable as digestion. Second, just like the Repetition Exercise, it is valuable in that it helps prime and improve the quality of our belief subset even further, and thus helps the Stoic to assent correctly to difficult impressions in the future.

In order to understand either of the two roles that the HE plays for Epictetus, we need to recall the important role held by both critical assent and a high quality subset of beliefs. The picture so far looks like this: in order to ensure we form correct beliefs Epictetus demands that we slow down the process through which we assent to impressions, making it purposeful and intentional rather than precipitate. This is critical assent. In doing so, we allow ourselves to be aware of the process of comparing a new impression to our beliefs, and determining that impression to be worthy of assent or not. But we do not compare that impression to a totality of beliefs, only to a subset of beliefs. Whether or not this impression seems true or contradictory compared to this subset is what determines if we assent or dissent to the impression. The beliefs that comprise this subset are determined, at least in part, by how often a given belief is utilized. The more 
often a belief is utilized, the more readily accessible and available it is during critical assent. Through the process of repeating Stoic doctrine to ourselves, we ensure that the subset contains important true beliefs, thereby making it more likely that we only assent to true impressions. It is the belief subset that provides evidence for belief modification, not the RE itself. This exercise plays a secondary role in ensuring that the belief subset is as high a quality as possible.

While the RE helps ensure that some truths make it into that subset of beliefs, this is not sufficient to ensure that we always assent properly. For a Stoic in training, commonly repeated beliefs do not possibly make up the entirety of their belief subset. When one is confronted by an impression, their belief subset will also contain plenty of other beliefs that are contextually specific to that particular impression. For example, when I am confronted by the impression of an object, this will evoke both the precepts and theory that I have kept "on-hand" through repetition, and as well as my specific beliefs about that particular object, be they good or bad, true or false.

However, for a Stoic in training many of these specific beliefs will be false. And it is foreseeable that these false beliefs, if persuasive and high in number, would be enough to cause us to assent to a false impression, even if the beliefs we keep "on-hand" are true Stoic precepts.

This is where, I propose, the HE comes into play as an important exercise. I argue that for Epictetus the HE is a process through which we develop specific beliefs about a certain subject by either indulging or abstaining from that subject in some way. Good habits develop true beliefs about a subject, bad habits develop false beliefs. If I have indulged too heavily in a bad habit, then I will have many false beliefs about the object of 
that habit. For example, if I have too often worked towards wealth and possessions, then I will have many false beliefs about the value of wealth. This is bad for two reasons. First, these false specific beliefs are a result of ignorance, and thus inherently bad. Second, these false beliefs will permeate my belief subset and make it difficult for me to assent to impressions successfully. Even if I am repeating Stoic doctrine to myself, my belief subset when it comes to impressions concerning wealth will be comprised almost entirely of false beliefs. As such, I will be unable to assent to true impressions concerning wealth and dissent from false ones, at least not with total accuracy.

The only way to counter these negative effects of the bad habit is to cultivate the good habit of living a minimalistic life. If I do so long enough, and without falling back into the bad habit, then I will develop true beliefs about wealth. For example, assuming the Stoics are correct that wealth or lack thereof does not impact our ability to have a good life, if I live without luxury for long enough I will realize through experience that my capacity for flourishing has not been impeded in anyway by my poverty. This will then cause me to form beliefs about how wealth is unnecessary for the achievement of a good life. These beliefs will then allow me to properly assent to all incoming impressions concerning wealth.

As stated at the beginning of this section, the goal of the HE is thus twofold. The HE causes true specific beliefs, which are in and of itself the digestion of theory and a moral virtue. And the HE also increases the quality of one's belief subset by filling it with true specific beliefs. This will allow the Stoic to assent correctly to more difficult impressions in the future. 
If we understand the HE in the way I proposed, then the following passages can be seen as coherent with intellectualism:

In general, then, if you want to do something, make it a habit; and if you want not to do something, abstain from doing it, and acquire the habit of doing something else in its place. This is also the case when it comes to things of the mind. Whenever you are angry, be assured that this is not only a present evil, but that you have strengthened the habit, and added fuel to the fire. When you yield to sexual desire, do not count it a single defeat, but know that you have fed, that you have strengthened your incontinence. For habits and faculties must necessarily be affected by the corresponding actions, and become implanted if they were not present previously, or be intensified and strengthened if they were. This is, of course, how philosophers say that sicknesses grow in the mind. When you once desire money, for example, if reason is applied to bring you to an awareness of the evil, the desire is curbed, and the governing faculty of the mind regains its authority: whereas, if you apply no remedy, it no longer returns to its former state, but when it is excited again by a corresponding impression, it is inflamed by desire more quickly than before, and, by frequent repetitions, at last becomes callous: and by this infirmity the love of money becomes fixed. For he who has had a fever, and then recovers, is not in the same state of health as before, unless he was perfectly cured; and something similar happens in sicknesses of the mind too. Certain traces and weals are left behind in it, which, unless the person concerned expunges them utterly, the next time he is flogged in the same place, not weals but wounds are created. If, then you do not wish to be ill-tempered, do not feed the habit. Give it nothing to promote its growth...For habit is first weakened, and then entirely destroyed. (2.18.4-13) 
At first glance such a passage seems intuitively incoherent with intellectualism. The notion of a vice becoming stronger or weaker through training seems to invoke the idea of an irrational part of the soul being either trained or neglected. But armed with the concepts of critical assent and belief subsets, we are in a position to understand how a habit can become stronger or weaker, even if we endorse intellectualism.

Epictetus says that when we indulge in a bad habit, such as desiring money, "certain traces and weals are left behind" in the mind. If the bad habit is left unchecked long enough, the weals become wounds. What could these metaphorical traces, weals, and wounds refer to? Recall that the Epictetan mind is only comprised of impressions, beliefs, an impulse to act, and our rational faculty. Epictetus cannot be referring to an alteration of the rational faculty, since it may not be altered or impeded in any way. It also does not seem as though he can be referring to impressions, since the same impression will be left regardless of whether assent is given or withheld. So if it was impressions to which he was referring, then these traces and weals would be left even if the bad habit was abstained from, which does not seem to be the case. This leaves only an impulse to act and beliefs. But impulses to act are ultimately reducible to beliefs. They are just a certain kind of belief with affective content. Therefore, the traces left behind when we indulge in a bad habit must be false beliefs.

What Epictetus is saying with this metaphor is that when one pursues money, their act forms certain corresponding specific beliefs about money. ${ }^{27}$ Since I am pursuing

${ }^{27}$ There seems to be a circularity present here. I.e. I pursue wealth because I believe it should be pursued, and I believe it should be pursued because I pursue it. However I do not think such a circle would be a problem for Epictetus who believes in our powerful 
money, these beliefs take the form of the notion that money should be desired, or that it is reasonable to desire externals. This is why Epictetus tells us that if "we have been long accustomed to do the opposite of what we should," then, "the opinions that we hold and apply are the opposite of the correct ones" (2.9.13). And these beliefs formed by my act then have implications in future belief formation. They will cause me to be "inflamed by desire more quickly than before". Then eventually, these beliefs become "callous: and by this infirmity the love of money becomes fixed".

This inflaming of desire and callousing of belief can easily be explained in cognitive terms when we consider belief subsets. When I form new false specific beliefs about the value of money, caused by my possessing and actively seeking wealth, these beliefs will from then on be present in my belief subset when I am presented with future impressions about money. I am inflamed by desire more quickly than before because my belief subset is now comprised of a higher ratio of beliefs that hold money to be valuable or desirable then it was previously. My belief subset also becomes more uniform. Thus the process of comparing the impression to my beliefs is quicker, with less hesitation, doubt or comparison necessary. The love of money becomes callous or fixed when, due to repeated indulgence, all the beliefs in my belief subset agree that money should be loved. At this point one's belief is fixed because one no longer has any beliefs to tell them otherwise. Loving money cannot be seen as contradictory or unhealthy if we have no beliefs to contradict this. This is the worst possible scenario and explains why bad habits

potential for autonomy and self-control. It seems that our rational faculty is able to, through constant vigilance, reflect upon its processes, recognize this circularity and then direct itself away from it. Thus the circularity of habits is only a problem for the nonstoic, but ultimately something the stoic in-training can overcome. 
are so detrimental to our moral therapy, even with our strong sense of autonomy and control over our assent.

This explanation also shows why the only possible way to fix the damage of a bad habit is with the contrary good habit (1.27.3). By practicing a good habit, it seems the identical process would happen in reverse. By practicing a life of poverty, and reminding myself of wealth's indifference, I develop true specific beliefs about wealth. In this sense, I am digesting the theory that I already know and repeat to myself. The theory is now be supported by true specific beliefs. When confronted by an impression, these true specific beliefs help me avoid desiring wealth quicker and more efficiently than before. As I continue digesting the theory by developing specific beliefs, I become less tempted by wealth, and the amount of wealth required to evoke desire must become greater. If done long enough, I would no longer have any beliefs about the value of wealth, and I would become protected. No amount of wealth or any variation thereof could incite my desire.

We are now in a position to understand why Epictetus puts such an emphasis on our actions when it comes to habituation. In Stoic psychology our actions do not alter our beliefs. Recall that the only thing that can modify our belief is evidence or a cognitive reason. But our actions give us a certain type of unique evidence or reason not found in theory. It is personal evidence about specific objects. If I want to live life free from desiring something, I should give that thing up. And in relinquishing that object, even if it was difficult at the time, I gain a unique perspective and evidence as to why I made the correct choice. This evidence allows me to justify and motivate my indifference. Thus when Epictetus says that when it comes to habituation we cannot be "contented with mere learning" but must "add practice also", (2.9.13) he is not saying that beliefs are 
insufficient for virtue, or that we require something besides rational reasons to modify our beliefs, or that habituation must require a non-cognitive aspect. He is saying that our potential to learn in the academic context is ultimately limited because it only offers general theory, not specific beliefs. In order for these to be able to properly cultivated, we must go out and act in the world. But we must also act properly.

All this considered, the picture evoked by talk of habituation is a constant battle between good and evil. Every act I make is motivated by an assent. Every assent I give forms a belief that either strengthens a good habit and aids in the digestion of theory or strengthens a bad habit and chips away at my progress. Each act of assent carries severe implications for my ability to be virtuous in the future. Thus every assent I give is of utmost importance, because I do not know what pervasive influence it might have on me. I must always be prepared and ready to take on any impression. Such a picture, far from being at odds with Epictetus' intellectualism, seems to fit perfectly within the Stoic theme of constant vigilance.

As Nussbaum puts it: "The Stoic idea of learning is an idea of increasing vigilance and wakefulness, as the mind, increasingly rapid and alive, learns to repossess its own experiences from the fog of habit, convention, and forgetfulness" (Therapy, 340).

Notice Nussbaum's phrase: "the fog of habit". Regardless of our intentions, we are constantly reinforcing our habits. Epictetus is not introducing habituation so much as he is encouraging us to ensure that we take control over this process, become aware of it, and ultimately make it intentional. Vigilance is needed so that we do not form false beliefs and reinforce our own ignorance. In other words, we need to practice critical assent to avoid forming bad habits, and to reinforce good habits. Habituation is too 
crucial a process to allow it to happen carelessly. Each bad habit requires long arduous work to counter with the opposing habit, and if left unchecked and unexamined these habits can run rampant in our lives. Our good habits must be repeatedly practiced to ensure that our true beliefs remain plentiful. If we do not make habituation intentional, it is unlikely or almost impossible that good habits can be maintained.

By now it should be clear why having students repeatedly practice the same habit does not contradict with intellectualism: the HE does not aim at modifying beliefs through non-rational means. Epictetus does not believe that a good habit will over-power our false beliefs and evil desires. Nor does he think that a bad habit forces us to do something against our better judgement. Rather our habits produce evidence in the form of specific beliefs. These specific beliefs are the evidence that modifies our other beliefs.

The cognitive role that habituation has in future belief formation should also be evident. The HE ensures that our beliefs about specific subjects, be they wealth, death, pleasure, pain, or otherwise, are of a high quality. Just like the previous repetition exercise of keeping proper Stoic doctrine accessible or "on-hand", this helps to ensure a high quality belief subset when faced with an incoming impression. It is the belief subset, cultivated through the HE and RE, that provides the evidence required for belief modification. The two exercises are thus used together.

Recall that when we are faced with an impression, our belief subset is composed of both relevant beliefs and beliefs often accessed or "on hand". If I see a lottery ticket, any impressions it causes will be tested against beliefs brought up by the specific object of the impression, in this case my beliefs about the value of wealth since it is a lottery ticket, and the beliefs I have on hand due to repetition. The purpose of the RE is to ensure that I 
have general beliefs and theory on-hand. The purpose of HE is to ensure that beliefs about the particular subject, in this case the value of a lottery ticket, are true. It is only when I have both that I can confident that critical assent will yield virtuous results. This means the HE and RE work together to help us perpetually form proper specific beliefs in accordance with our theory. In unison they allow continued successful digestion of these precepts.

\subsection{Questioning Exercise}

At this point we have looked at two of the three types of repetition exercises utilized by Epictetus. The first, presented by Braicovich, was the demand for us to keep precepts on hand and accessible. The second was the importance Epictetus placed on the performing of proper actions so as to develop proper habits. Both of these were demonstrated to be coherent with Epictetus' conception of psychology when understood as being directed towards digesting theory through the formation of correct specific beliefs. They do this is by ensuring that when we engage in critical assent we have a suitably high quality subset of beliefs. It is this high quality belief subset, in conjunction with critical assent, which allows us to assent to proper specific beliefs.

The third spiritual exercise aims to help this process, albeit in a different way. It is directed at ensuring that we successfully engage in critical assent in the first place. If we fail to begin critical assent, then the previous exercises are rendered useless, because when performing precipitate assent we have no guarantee about what belief subset the impression will be compared to. 
Section 4.3 is dedicated to describing the particular exercise and how Epictetus presents it in the Discourses, while Section 4.4 is aimed at demonstrating how the exercise can be shown to be directed towards the digestion of theory through the formation of specific beliefs in accordance with that theory.

For Epictetus critical assent is one of the cornerstones of moral progress. It is the first and greatest task of any philosopher (1.20.7). It is one of the five most important intellectual powers possessed by a true philosopher (2.8.29). Without critical assent, moral progress seems impossible, as we will be "carried away" by the strength of every impression that presents itself to us (2.18.24).

As such it is no surprise that Epictetus demands critical assent from his students. And yet within the Discourses Epictetus does more than just demand critical assent, or remind his students of its importance. To ensure their moral progress, he prescribes an exercise to help them practice their critical assent. The exercise is to go out into the world and discover the question in every impression. He commands them to do this daily at every opportunity, in an exercise that I call the Questioning Exercise (QE):

In the same way we exercise ourselves to deal with sophistical questioning, we should exercise ourselves daily to deal with impressions; for these too put questions to us, 'So and-so's son is dead. What do you think of that?' It lies outside the sphere of choice, it is not an evil. - 'So-and-so has been disinherited by his father. What do you think of that?' It lies outside the sphere of choice, it is not an evil. - 'Caesar has condemned him.' - This lies outside the sphere of choice, it is not an evil. - He has been distressed by this. - This is within the sphere of choice, it is an evil. - He has borne it nobly. - This is within the sphere of choice, it is a good. (3.8.1-3) 
This passage has two components. The first component is identifying the question that all impressions put to us. This is the part I am interested in. The second component is that we obviously want to answer this question correctly. As such, Epictetus calls for the student to always bring to mind whether the question falls within or outside of the sphere of choice, and to then properly employ that knowledge in answering the question. While essential to his overall program, this second component incorporates the Repetition Exercise, described by Braicovich, and the Habituation Exercise. These two exercises have already been addressed.

The point of the QE is not to make a question out of nothing. According to the Stoics, every impression already presents us with a proposition, whether we realize it or not. These propositions, regardless of our awareness of them, bring with them a question. At the very least they can be true or false. Epictetus phrases the question in the above passage as "what do you think of that?". Recall that this question may only be answered in three ways. Either we think the proposition is true, and we assent, we think the proposition is false and we dissent, or we deem the proposition unknowable and we withhold assent. However in almost all circumstances these questions are never made salient to us. This process occurs and the question is answered without us realizing. This is precipitate assent.

The purpose of the QE then is to make these hidden questions explicit and cognizant. One cannot intentionally answer the questions impressions present us with without being aware of them. In other words, I cannot begin the process of critical assent unless I 
realize I am being presented with a question. Thus identifying the question implicit in every impression is necessary for critical assent.

This exercise is a central part of Epictetus' curriculum. It is called for throughout the

\section{Discourses:}

Go out at the break of dawn, examine whomsoever you see or hear, and then answer, as if to a question. What have you seen? A handsome person? Apply the rule. Is this within the sphere of choice or outside it? Outside it. Throw it away. What have you seen? One grieving for the death of his child? Apply the rule. Death is outside the sphere of choice. Throw it aside. A consul met you? Apply the rule. What kind of thing is a consulship? Within the sphere of choice or outside it? Outside it. Throw this aside too. It does not stand the test. Fling it away. It is nothing to you.

If we had acted thus, and trained ourselves in this manner from morning till night, then, by the gods, something would have been achieved. Whereas now, we are caught half asleep by every impression, and if we ever do wake up, it is only for a little in the lecture-hall. And then we go out and if we see anyone in distress, we say, 'He is done for'; if a consul, 'Happy man!'; if an exile, 'What misery!'; if a poor man, 'How wretched for him; he has nothing to buy a meal with!' $(3.3 .16-17)^{28}$

\footnotetext{
${ }^{28}$ It is worthwhile to break down this passage in greater detail because it demonstrates all three spiritual exercises in action. In this passage Epictetus is asking his students to go out in the morning prepared to face impressions. They are expected to proceed cautiously, interrogating everything they encounter impression by impression, not allowing any to go unscrutinised. Once they identify an impression, they are to recognize the proposition it brings with it. In this particular passage, Epictetus is focusing on propositions concerning the value or disvalue of something. First we encounter a beautiful man. This impression would carry with it the proposition "his beauty seems to be a good thing, do you agree?" This is the Questioning Exercise. Now that we have identified the impression and its question, and refrained from giving precipitate assent,
} 
In this passage, Epictetus is demanding that his students form a question of every impression. They must ask themselves what they have seen, and find the proposition implicit within it. For Epictetus this is necessary for critical assent. If we do not engage in this kind of training then regardless of how well we are prepared in other areas we will still be "caught half asleep by every impression". It is clear that we must practice identifying and forming the question implicit in every impression, or else we will be perpetually stuck in precipitate action.

Epictetus reiterates this again in the Handbook:

With regard to everything that befalls you, remember to turn towards yourself and ask what capacity you have for making a proper use of it. If you see a beautiful boy or woman, you will find self-control the capacity to use against this: if you are subject to pain, you will find endurance; if abuse, you will find patience. If you become used to this, impressions will not carry you away. (Handbook, 10)

At first this may seem to be a different exercise. Epictetus is asking students to find the corresponding virtue required to respond properly to impressions. But the question forming is implicit here. I need to first identify what kinds of impressions I am being confronted with before I can know whether they require self-control, endurance or

the process of critical assent begins. We then answer the question properly by keeping at hand Stoic doctrine. This is referred to by Epictetus as "applying the rule". This correctly answered question then contributes to our habituation in the form of a specific belief. With this correctly formed belief, I have strengthened my good habit of recognizing physical beauty to be indifferent. This passage perfectly demonstrates all three spiritual exercises. 
patience. In other words, different impressions require different responses because they present to us different questions. It is only by becoming aware of these questions that we can learn to properly identify and respond with the according virtues. Thus for Epictetus the only way to not be carried away by impression is to question what we see.

It must be practiced repeatedly "from morning till night". We must "exercise ourselves daily" in the QE if we plan to be successful at performing critical assent. If we fail to repeat this exercise and only identify the questions in our impressions on occasion, we will be like the students who wake up for a time in the classroom only to fall right back into precipitate assent as soon as they leave. It is clear why Epictetus views question forming as a necessary exercise: It is a required part of the process of critical assent. This, in turn, is an essential aspect of our moral progress as philosophers.

Unlike the previous two exercises, this exercise intuitively seems to fit pretty well with intellectualism. Perhaps this is because it does not seem in any way to be aimed at the modification of belief. However, it is still worthwhile to discuss the exact role the QE has on a psychological level for Epictetus. Is it modifying our rational faculty? Is it an already present function of our faculty that we are training ourselves to employ? These are questions worth examining in order for us to be able to understand exactly how the QE was conceived of by Epictetus. Once answered we will be in a position to properly understand exactly how the QE aids with the digestion of theory. 


\subsection{Questioning Exercise and Specific Beliefs}

First it should be clarified that repeatedly practicing the QE does not modify the rational faculty in any way, nor is it intended to. Recall that for Epictetus the rational faculty, in virtue of its very nature, is already self-reflective:

What will tell you, then [whether it is appropriate to play music at a particular time]?

The faculty which contemplates both itself and all other things.

And what is that?

The reasoning faculty; for that alone of the faculties that we have received comprehends both itself - what it is, what it is capable of, and with what valuable powers it has to come to us - and all the other faculties likewise. (1.1.4)

The rational faculty already comprehends itself, its capabilities, and all other faculties of the mind. It therefore does not need to be modified in any way to allow for critical assent. In the process of our constant precipitate assent, the rational faculty already reflects upon incoming impressions, formulates them into questions, and answers these questions through the giving or withholding of assent. The purpose of the QE then cannot be to train our rational faculty to make questions out of impressions. Rather, its purpose is to train ourselves to focus our attention upon this naturally occurring process. We are training ourselves to become aware of what the rational faculty already does.

To use an example, think of yourself now, reading this thesis. If you are finding this thesis particularly engaging then your focus is probably dedicated to it alone. But now I ask you to direct your attention to other stimuli, like the ambient sound of the 
room, the feeling of your body against your chair, or the feeling of your toes inside your shoes. Now that your attention has been refocused you are able to perceive these physical sensations, even though they were unknown to you just moments ago.

But this information was already being relayed to your mind, even before you directed your attention to it. Your body is constantly receiving information from everywhere and through all of its senses. Thus when we focus our attention upon on a certain object, we are not altering the kind of information we receive, rather we are prioritizing it. Our attention is used to focus and limit the information we want to make relevant to ourselves. This allows for greater focus, and the completion of more difficult and nuanced tasks. One would not be able to read a philosophical paper if every piece of physical stimuli received just as much cognitive priority as each word upon the page.

Thus we remain unaware of the other stimuli until some great change directs our attention towards it. I might not realize I am hearing the conversations in the library until I notice someone say my name. Or I might forget I even have legs until a spider bites one and my attention is focused upon them again.

The Stoic picture is the same. The non-stoic is constantly 'asleep', swept away unaware by each impression. They go through life giving only precipitate assent until some sudden important impression reminds them that they have a reflective faculty that they may employ critically, just as some sudden noise reminds a focused reader that they still have hearing. The QE demands from us that we never waiver in our constant attention and vigilance. It demands that we treat every impression as important, and that we discover the implicit question. This exercise is necessary because, for Epictetus, every impression is an important one. Every impression is an opportunity to endorse falsehood, 
and thereby fall into the evil of ignorance. Thus he demands that each impression must demonstrate to us that it is true and corresponds to nature before we may assent to it (3.12.15).

This may sound extreme, but let us return to the example of the non-stoic who does not practice the $\mathrm{QE}$. The non-stoic will still prioritize certain impressions, but they will have a distorted view of what an important impression is. The non-stoic may spend a day deliberating, trying to decide if they should buy a red car or a blue car. They carefully examine and compare their specific beliefs about which colour they prefer, or about which is more likely to impress their friends. But unbeknownst to our non-stoic, to get to this point they have already given assented to multiple false impressions. They have already given their precipitate assent to impressions such as "it is good to own a car", and "material possessions will make me happy". Their reflections upon these impressions are immeasurably more important for their well-being than what colour car they buy. Yet they will spend all their time deliberating upon the impression "a red car is better than a blue car". But it is too late to go back. They have already given their assent to the really important questions. They were just 'asleep' when it happened.

The reason I am explaining this process in such detail is to demonstrate that there is no modification taking place. The question forming exercise in no way alters the rational faculty, nor does it make it stronger in any way. Our rational faculty constantly receives impressions, reflects upon them, and gives assent to their implicit questions whether or not we are aware of this process. The exercise only asks us to draw our attention to what is already happening. 
Now we are in a position to understand how this exercise relates to the digestion of theory. Up to this point I have argued that spiritual exercises do not conflict with intellectualism because they do not aim to modify our beliefs through non-rational means. Rather I have argued that their aim is to allow for the digestion of theory. The digestion of theory refers to formation of specific beliefs that are in accordance with theory, which is general and non-specific by nature. I argue that it is these correct specific beliefs which, in unison with theory, provide the evidence required to modify belief. This is wholly compatible with intellectualism. We have seen how RE and HE aid in this process by improving the belief subset during critical assent. They stack the evidence in favor of the truth. In turn, this makes us more readily able to assent to true impressions and to dissent to false ones.

The purpose of $\mathrm{QE}$, as a spiritual exercise, is to simply enable critical assent to occur. In doing so, it allows the progress made by the other two exercises to be at their most effective. Recall that when we engage in critical assent, we delay the process of assent and make it intentional. This allows us to intentionally and purposefully refer back to our own beliefs. In this way we can, with at least some control, intentionally prime and select a suitable belief subset. If I have been practicing both RE and HE, then the subset I intentionally compare this impression against will be of a high quality and I will assent correctly.

It is important to be clear; critical assent alone does not necessitate a proper or virtuous assent. It is not sufficient because if my theory and specific beliefs are wrong I will assent incorrectly, even if I slow down the process to make my assent intentional. Nor is critical assent even necessary. We assent to true impressions through precipitate 
action all the time. Rather the majority of true beliefs held by a non-Stoic, and even a Stoic in training, would be achieved through precipitate assent. But what critical assent does do is maximize my chances of assenting correctly, and thereby minimize the chances of me assenting improperly. If I practice critical assent and still assent to a falsehood, then I have done so because I am significantly ignorant and I could not have known better at the time. The remedy to this ignorance is the continued study of theory, and practicing of spiritual exercises. But what is worse, and inexcusable to Epictetus's teachings, is if I possessed the rational tools and evidence to assent correctly, but failed to do so by allowing myself to be "swept away unaware" by the impression. This would be an avoidable false belief, and thus an avoidable evil. The role of QE is to make sure that this never happens. It ensures that when critical assent occurs we maximize our potential to assent correctly. In conjunction with the RE and the HE, it allows for the correct formation of specific beliefs, and thus, for the digestion of theory. 


\section{Chapter: The Athlete Analogy}

In Section 3.1 I proposed my own original interpretation of how Epictetus conceived of the role which spiritual exercises play in our moral progress. In Chapters 3 and 4 I explored three spiritual exercises in Epictetus, and explained how they fit within my interpretation of spiritual exercises. While I believe this to be convincing by itself, my argument does lack any sort of explicit endorsement by Epictetus himself. Unfortunately, it is the nature of the Discourses and The Handbook to not be explicit. Epictetus never states clearly the exact purpose of these spiritual exercises. However, I think a purpose in line with the one that I have proposed can be inferred from the text. More specifically, I think it can be inferred from the comparisons Epictetus draws between the Stoic and the athlete. Accordingly, my goal in this final chapter is to examine this analogy.

\subsection{Specific Beliefs and Muscle}

At this point I have explored three spiritual exercises within Epictetus, and demonstrated that they serve a coherent and necessary role within his philosophy, despite seeming prima facie to be at conflict with his intellectualism. We have seen that, contrary to Brennan's concerns, none of these exercises were intended by Epictetus to modify beliefs through non-rational means. Rather, their purpose is to allow for the digestion of theory through the formation of specific beliefs.

But for Brennan, even if spiritual exercises are coherent with intellectualism their necessity is still worrisome. To him it is a lesser form of progress than should be the case with intellectualism. He argues that we lose something special about Stoic moral therapy if we reduce it to the level of spiritual exercises. As already mentioned above Brennan 
says that even if we can find a coherent role for repetition with Epictetus "we should at least be disappointed when the bright Socratic hope of rationally arguing our way to virtue is replaced by the grim Epictetan tedium of catechetical pushups" (Moral Psychology, 279).

But why should we be disappointed? The portrayal of a bright Stoic intellectualism is a caricature, and the judgement of spiritual exercises is a bias. Epictetus does not once describe the therapeutic process of a unified rational self as being without conflict, struggle or hard work. Achieving virtue is not a harmonious or immediate process, but rather a long gradual process that requires arduous vigilance, dedication, and commitment to one's training, not just in theory but also in practice. Nor is such training inconsistent with his intellectualism, or somehow a lesser form of progress than pure rational argument. For Epictetus, training is a necessary part of dealing with our own plentiful ignorance.

In order to make this clear, Epictetus presents his own analogy. Rather than the charioteer and horses of Plato's Phaedrus, Epictetus repeatedly describes the practicing Stoic as kind of athlete, and nothing is more essential to the life of an athlete than exercise, conflict and training. In fact, Brennan is accurate to describe Epictetan progress as being analogous to push-ups, or physical exercise. The difference is that for Epictetus, this is not a disappointment. It is the way progress works. An in-depth analysis of this analogy between Stoic and athlete will provide much evidence to support my interpretation of the role played by spiritual exercises.

The first comparison that I explore is the comparison Epictetus makes between the muscles of an athlete and the Stoics' correct specific beliefs. In the following passage 
Epictetus compares a student who takes pride in having memorized lessons, rather than being able to successfully implement those lessons, to an athlete who brags up his weights rather than his muscles:

'This man here', someone says, 'is already able to read Chrysippus, even by himself.' - By the gods, that is good progress you are making, man. What progress! 'Why do you make fun of him?' - And why do you distract him from an awareness of his deficiencies? Are you not willing to show him what virtue brings about, so that he may know where to seek his progress? Seek it in that place, wretch, where your task lies. And where does your task lie? In desire and aversion, that you may neither fail to attain what you desire, nor fall into what you want to avoid; in exerting your impulse to act and not to act, that you may not be liable to error; in assent and the withholding of assent, that you may not be liable to be deceived. The first areas of study are the first and most necessary. But if, trembling and lamenting all the while, you seek never to fall into misfortune, how, I ask you, are you making progress?

Show me then your progress in this point. It is as if I were talking to an athlete and said, 'Show me your shoulders', and he then replied, 'Look at my jumping-weights.' That is quite enough of you and your jumping-weights: what I want to see if what the jumping-weights serve to achieve. (1.4.9-13)

What Epictetus focuses in on as a measure of progress is both the holding of correct specific beliefs, and the formation of correct specific beliefs. These correct specific beliefs are the muscles of the Stoic. In order for you to "neither fail to attain what you desire, nor fall into what you want to avoid" you must already hold correct beliefs about the indifference of externals. But you must also ensure that in both giving and 
withholding assent "you may not be liable to be deceived". This means that even if you already hold correct beliefs, you must not be deceived by incoming impressions. Progress is measured by taking stock of both the correct beliefs we hold, as well as our ability to not form ignorant and false beliefs.

As an excerpt from a chapter titled "On Progress", this passage serves first and foremost as a warning about mistaken or false progress. The point that Epictetus is making, and the nature of his disagreement with the others, is that progress is measured by your subjective experience, not your superficial knowledge of doctrine. What is being measured when we measure progress are the specific beliefs we have, not our knowledge of which specific beliefs theory tells us we should have. For example, what is being measured is if you actually fail to attain what you desire. If you fail, it is because you still value that which is external to you; you still have incorrect specific beliefs. And if this is the case, then you have no advantage over an untrained Stoic just because you possess the theory. You are not better than someone else just because you know the Stoic theory that you should not value externals if this theory is not reflected in your specific beliefs. You and the untrained Stoic still both value externals in your specific beliefs, thus you are both still identically ignorant in this respect.

Epictetus is emphasizing that the tools we use for progress do not have inherent value. What are valuable are the changes that the tool creates. Knowing the theories of Chrysippus is a tool. In fact, it is an essential tool. Epictetus tells us that "the first areas of study are the first and most necessary", referring to theory. We require these theories to aid us in creating correct specific beliefs, just as we require jumping-weights in order to 
create muscles. But an athlete is a fool if he goes around showing off his jumpingweights if he has not developed any muscle.

In another passage, Epictetus returns the analogy between an athlete's muscles, and a philosopher's correct specific beliefs:

Those who have learned precepts as mere theory want to vomit them up immediately, just as people with weak stomachs do with their food. Digest your precepts first, and you will not vomit them up in this way; otherwise they really do turn to vomit, tainted matter unfit to eat. Then show us some change that results from those precepts in your own ruling faculty, just as athletes can show their shoulders as the results of their training and diet... (3.21.1-3)

I have quoted this passage twice before, in Sections 2.3 and 3.1, but those were both in the context of explaining the process of digestion. Now let us look at what digestion means in relation to the athlete analogy. Epictetus is again attacking people who rely exclusively upon theory as a measurement of progress. Theoretical precepts must first be digested; they must produce or change into specific beliefs. Only then can they be called progress.

The comparison between the muscles of an athlete and our specific beliefs is most explicit here. Just as physical digestion changes the body, digestion of theory changes the mind. This change can be rightfully called progress for both the athlete and for the philosopher. If there is not some change in our ruling faculty, either in our ability to perform successful critical assent, or in the amount of correct specific beliefs we hold, then there cannot be any true progress. This is no different to how an athlete must be able 
to show a change in their body composition in order for them to claim that they have made any progress from their training and diet. Also, a diet that one eats and vomits before digesting it will be insufficient to change their body, just as only studying Stoicism in theory is insufficient for moral progress.

While this analogy helps us understand the purpose of spiritual exercises in Epictetus' philosophy it also has some important implications. The first implication is that training is a necessarily a transformative process. The merit of exercises is determined by whether or not they enact some change upon the self. Since the ruling faculty itself cannot be changed, and is unalienable in nature, this change must be found in the beliefs we hold. What is interesting about this is that despite Epictetus believing that all humans have a divine rational faculty, through training we transform and change. We become different, and a result of this difference is that one is able to do what they could not do before, and what others who have not transformed cannot do.

Just as the athlete, armed with muscles enlarged through training, can lift a weight that a skinny civilian cannot, so can the Stoic overcome the inclination to assent to persuasive false impressions that a regular person could not help but be swept away by. For the Stoic is armed, not with muscle, but with proper specific beliefs honed through the Habituation Exercise and the Repetition Exercise, and facilitated by the critical assent practiced during the Questioning Exercise. This means that even though all humans possess reason, we are not all equal in our ability to make use of it. It may in fact be the case that a non-stoic cannot help but be swept away by grief at the death of their loved one. It could be that they simply do not possess the mental muscle required to withhold assent. This is not to say that they could not train themselves over time, but the analogy 
does seem to imply that you must confront each impression with the progress you currently have made, and not all people have reached the same level of progress.

This means that progress must be incremental. I cannot attempt something beyond my current level of progress. Epictetus returns to the athlete metaphor in order to discourage those who wish to attempt acts beyond current progress: "So, unable as we are to fulfil the profession of man, we take on in addition that of the philosopher, such a massive burden besides. It is much as if a man who was incapable of lifting ten pounds aspired to raise the stone of Ajax" (2.9.22).

Epictetus considers becoming a true philosopher to be the apex of our progress. Becoming a philosopher is the culmination of years and years of work, dedication and practice which produces a significant transformation of the self. This transformation is a necessary step to becoming a philosopher. For Epictetus it would be as absurd for an untrained person to attempt to be a philosopher as it would be for a person without muscles to try to raise the stone of Ajax. If such a feat is possible, it will only be achieved through hard fought progress and transformation over a prolonged period of time. For the athlete this is the transformation of the body, and for the Stoic in training it is a transformation of specific beliefs, the digestion of theory. For Epictetus only such transformation can be rightly called progress, because only such transformation makes our beliefs more virtuous, and gets us closer to our eventual goal of being a proper philosopher or sage.

There are ways to explain that progress is a kind of development of proper specific beliefs without using the athlete analogy. We have to assume that the analogy was intentionally chosen by Epictetus because it accurately represents the nature of 
developing specific beliefs. As such, we can infer additional things from it. Perhaps the most interesting thing about choosing to represent specific beliefs as muscle is that muscle atrophies. Muscle is not static, it either develops or recedes. It gains size and strength, or it loses it. Training then is not merely a means to make muscle stronger; it is also a means to maintain the strength you already have. Thus we can infer that Epictetus conceived of our mental progress along the same lines.

We are constantly bombarded by impressions. Facing these impressions with our spiritual exercises in hand makes us stronger, and so we progress, transforming ourselves for the better. However, if we cease practicing these exercises, if we no longer question incoming impressions, or repeat theory to ourselves, or develop proper habits, then we lose our progress. We will be swept away by impressions, or we will perform critical assent but endorse false impressions anyway. Our progress fades because we no longer exercise, just as a strong athlete who is bedridden loses muscle. Thus, spiritual exercises have necessarily repetitive aspects. They must be constantly done, over and over again, or else we will lose what progress we have gained.

This fits perfectly with the Stoic concept of vigilance. Under such a picture we cannot decide when we want to exercise. As Stoics, we must always exercise because we are always being faced with impressions. We must be vigilant and repeat our exercises no matter the progress we have already made. A proper Stoic never rests from their vigilance, or gives up their exercises, for doing would be to lose their progress altogether. Imagine for example a competent Stoic, someone who is not yet a sage but certainly able to distance themselves from externals, remove most of their passions, and limit the ones they do have. Perhaps this person is an educated politician like Marcus Aurelius. They 
possess a strong theoretical understanding of Stoicism, and every day they apply their exercises to the incoming impressions that face them. Now imagine if that person keeps the same life they had, but ceased thinking about Stoicism, or practicing any Stoic exercises. I am not going so far as to say they must submerse themselves in ignorance, only that they cease being vigilant, and cease exercising. We can expect that in a short period of time, perhaps only a matter of years, they would lose all their progress. Like a great athlete who stops doing push-ups and lifting weights, their mind would atrophy. Progress would be lost. We can see from this why the muscle analogy appealed so much to Epictetus: it evokes images of effort, transformation, and the need for repetition and vigilance.

\subsection{Impressions as Wrestling Opponents}

If our specific beliefs are like muscles, what do we use those muscles for? To defeat our wrestling opponents, says Epictetus. And what are our wrestling opponents? They are the hardships of life, the incoming impressions that cause ignorance and suffering if they are assented to. Epictetus continues the analogy between Stoic and athlete by comparing the Stoic who faces difficulties in life to a wrestler facing a fierce opponent:

Difficulties are the things that show what men are. Hence-forth, when some difficulty befalls you, remembers that god, like a wrestling-master, has matched you with a rough young man.

For what end? That you may become an Olympic victor and that cannot be done without sweat. No man, in my opinion has a more advantageous difficulty on his hands that you 
have, if only you will but use it as an athlete uses the young man he is wrestling against.

God, like a wrestling coach, has placed powerful opponents before each of us in the form of hardships. Epictetus implores us to realize that these situations are not genuine evils, but rather opportunities to demonstrate our progress. If we are able to best our opponent, then we have shown what we have truly learnt about what is up to us and what is not. Vanquishing this wrestling opponent means handling the hardship virtuously, that is, to not allowing it to evoke passions, or cause us to assent to false impressions. Even if we fail, this still serves as an opportunity to learn. Just like being beaten by a better wrestler is an opportunity to reconsider one's technique.

The analogy fits in perfectly with the comparison between specific beliefs and muscles. The more muscles a wrestler has and the more developed their physique the stronger opponents they are able to defeat. Likewise, this analogy is decidedly practical. The Stoic is not a body builder who shows off his muscles for the sake of it. The Stoic is an athlete. The athlete's muscles are only valuable in so far as they allow them to out wrestle other wrestlers. Likewise, the progress we make when practicing Stoicism only really reveals its value when we face a difficult situation. It is in these situations that we are thankful for the work we put into our spiritual exercises, for they have given us the proper specific beliefs required to make it through the hardship virtuously. Likewise, it is only when the wrestler is picking up her opponent that she can truly appreciate the value of all the grueling push-ups and exercises she has done. It is only because she has done 
these, transforming her body, that she is able to lift her opponent and throw them to the ground.

An important implication of Epictetus comparing hardships in life to wrestling opponents is that these hardships must be seen as beneficial, and ultimately essential, for our progress and for our therapy. They teach us what we have left to learn, and show us where progress still has to be made. One may think that they understand a certain Stoic theory, and that their specific beliefs are in accordance with that theory, but they cannot really be sure until they are faced with a difficult situation. One may study the theory as to why they should not be angry at others, and they may try to digest this theory by habituating a calm demeanor, but progress cannot be truly measured until one is tested by a truly venomous bully. One remains calm and defeats the opponent, or one is provoked into anger and defeated. But in defeat one has still learnt a valuable lesson: they now know where to direct their future training.

A consequence of this is that Stoics should try to seek out the kind of life that will contain difficult situations. I do not mean this in a masochistic sense, and one should not go to an extreme. Recall from the previous section that progress must be incremental. A balance must be obtained; both victory and defeat are necessary. A wrestler who only ever loses matches has no opportunity to gauge their progress, but neither does the wrestler who only ever wins. Thus difficulties that are able to defeat us are essential to measuring our progress. This explains, at least in part, why the Stoic in training is never portrayed as isolated or removed from society. Epictetus does not encourage his students to go out and live in the wilderness, or to remain at the academy surrounded by other Stoics for the rest of their lives. There is the most to be learnt in the city surrounded by 
other people and the difficulties they bring. Just as the wrestler who wants to become Olympic champion must be training at a skilled academy with excellent teammates, the Stoic must ensure they are surrounded by difficulty if they want to ensure progress.

Difficulties, far from being something that we should begrudgingly endure, are conceived of as both necessary and good. In fact, Epictetus goes so far as to say that a Stoic should eventually become excited by difficulties and be disappointed by their absence:

When we are called to meet some difficulty, we should know that the time has come to show whether we have been well educated. For a young man who goes from his studies to confront such a difficulty is like a person who has practised the analysis of syllogisms, and if somebody proposes an easy one, says, 'Give me, rather, a fine intricate one, that I may get some exercise.' So also are wrestlers displeased when matched with lightweight young men. 'He cannot lift me', one says, 'now there is a fine young man.' (1.29.33-35)

Epictetus expects the practicing Stoic to be disappointed when they are presented with a situation that is not difficult for them. Such a situation yields no opportunity to measure and test their progress. This is just the same as how a student of logic will want to test herself against a difficult logic puzzle, and a wrestler will want to be paired with a difficult opponent. The student, be it of Stoicism, wrestling or logic, desires progress, and difficult situations are necessary for progress.

We are now in a position to see what Epictetus actually says about how moral progress works within the framework of Stoic intellectualism. Developing proper specific beliefs requires repetition, vigilance, commitment and above all hard work. Testing our 
progress requires that we face situations we do not desire to be in. Epictetus recommends a training program that is gritty, difficult, and full of conflict. Epictetus' therapy is far removed from the idealized portrayal of "the bright Socratic hope of rationally arguing our way to virtue" that Brennan proposes.

Training to be a Stoic is like training to win the Olympic Games. While there is glory in victory, there is nothing pretty about the process. Consider what Epictetus says about training to win the Olympics:

You must conform to the discipline, submit to a diet, refrain from pastries; train under order, at an appointed hour in heat or cold; you must not drink cold water, nor ever wine as you like. In a word, you must give yourself up to you trainer as you would a doctor. Then, when it comes to the contest, you have to compete in digging, and sometimes dislocate your wrist, twist your ankle, swallow and abundance of dust, get whipped, and ever after all that you are sometimes defeated. $(3.15 .2-4)$

Training to be a Stoic is no different. One risks pain and injury, they are forced to give up luxuries, they must follow the instructions of their teacher, and after all this they may still be defeated. It is grim but for Epictetus it is how it works.

\subsection{The Glory of Victory}

At this point, the athlete analogy may seem a bit brutal. The Stoic is forced to undergo rigorous training and practice in order to progress. This progress requires constant repetition just to maintain. Finally, in order to continue progressing we must 
actively seek out situations that are difficult and unpleasant. Conflict and struggle, things people typically try and avoid, are actually necessary, encouraged, and should be desired. This may sound like a ruthless training program to some, but Epictetus denies that this picture is as grim as it seems. Thinking of it this way focuses on the negative aspects and ignores the positive results. The life of an Olympic athlete may be hard, but the rewards ultimately outweigh the difficulties. The same is true for the philosopher. In fact, the philosopher's life is even better, because the athlete only has the opportunity to win the Olympic Games once every four years, whereas the philosopher has an opportunity to achieve glory every time they are faced with an impression.

Epictetus compares overcoming difficulties to a victory on par with winning the Olympics, and deserving of the same glory and recognition. He provides the example of Socrates successfully not coveting or valuing Alcibiades' physical beauty:

Go to Socrates, and see him lying with Alcibiades and laughing off the young man's beauty. Consider what a victory he was conscious of obtaining, what an Olympic prize, and what rank he held amongst the successors of Heracles. So that, by the gods, one might justly greet that man with the cry, 'Hail, wonderful man!', as against those putrid boxers and pancratiasts, and those who are just like them, the gladiators. (2.18.22)

Socrates' ability to not be fooled by temptation is a virtuous response to a very tempting impression. The virtuous response is compared to an "Olympic prize" by Epictetus. Now obviously the Olympics connote a sense of greatness. Winning an Olympic Game was something desired and admired by all people at the time of Epictetus' writings. But there are other ways that Epictetus could try to communicate excellence. 
And if Epictetus was trying to tempt us into being Stoics by comparing achieving virtue to achieving riches and fame, this seems decidedly contradictory to his otherwise prevalent detachment from the conceptions of the value of those external goods. There must, it seems, be some other reason Epictetus relies upon such a comparison.

Epictetus chooses to represent virtuously dealing with impressions as an Olympic victory because it is a continuation of the athlete analogy. Consider what the Olympic Games means to an athlete. Not only is it the greatest opportunity for glory possible, but it is also the culmination of all the athlete is worked for; it is their reason for training. The idea of Olympic glory serves as their ultimate guiding purpose when enduring the hardships of training. Not only is it an objective, but it is the objective. It is the ultimate end. The wrestler does not train for the sake of their muscles, nor does the wrestler train to beat other wrestlers. The wrestler does these things in order to win the Olympic Games. Victory is the end in and of itself for the athlete. Achieving virtue plays the same role for the Stoics. The Stoics train and exercise so that they may come to hold correct beliefs and thereby becoming virtuous.

Another important point of the analogy is that it allows us to properly explain what is at stake with any impression that carries a value proposition. The Stoics are not permitted to ever let down their vigilance. It is not reasonable to allow the majority of impressions to go unexamined and then only employ critical assent for decisions we deem important. This makes no sense, because every decision is important. For every impression our corresponding assent will either be ignorant and evil or reasonable and virtuous. In the Handbook, Epictetus reminds us that "with anything that is burdensome 
or sweet, or glorious or inglorious, remember that now is the time of the contest, and the Olympic games have arrived" (Handbook, 51).

Thus everything we encounter in life, good or bad, significant or indifferent seeming, is an opportunity to showcase the results of our training, as well an event of significant importance according to Epictetus. However, while every assent is of Olympic importance, even if you fail to exercise your assent properly, the Stoic does not have the same reasons to be discouraged as an Olympic athlete would. Even if we fail and are swept away by an impression, or mistakenly assent to a falsehood, nothing stops us from achieving glory when confronting the next impression. Epictetus says that "even if we falter for a time, no one prevents us from renewing the contest, nor need we wait another four years for the next Olympic Games to come" (3.25.1-4). So while the athlete can only compete every four years, the Stoic is privileged in that they are free to compete every day. Epictetus is trying to show us that if we turn what we value away from externals and towards virtue, then all of us have the opportunity to achieve excellence and glory regardless of our previous circumstances, even if we have failed before.

Epictetus is conveying is that Stoicism, despite requiring effort and struggle, is not a grim or defeatist undertaking. To the contrary, practicing Stoicism will lead the average person to a kind of excellence and glory that is typically thought of by the nonphilosopher as being only reserved for a select and elite few. The point here is that the life of a Stoic is like the life of an Olympic champion: difficult but justified. An Olympic champion must work, practice, and struggle for years in order to maintain their physique and technique. But when they are crowned champion of the Olympiad, no one would ever dare to say that the struggle was not worth it. Seen in this way, the athlete analogy is 
optimistic and empowering, while still being honest about the commitment and sacrifice required to achieve virtue.

\subsection{Conclusion}

My goal has been to provide an interpretation of spiritual exercise which is coherent with intellectualism, not reducible to theory, and essential for moral progress. I argued that the purpose of spiritual exercises is to digest theory, with digestion referring to the formation of correct specific beliefs that are in accordance with Stoic theory. From there, I examined Epictetus' three spiritual exercises in particular, and explained their particular contribution to digestion. These are as follows:

1) Repetition Exercise: Ensures that correct theory and precepts are available to us during critical assent.

2) Habituation Exercise: A) Causes the formation of correct specific beliefs and B) ensures that correct specific beliefs are available to us during critical assent.

3) Questioning Exercise: Supports the other two exercises by ensuring that critical assent occurs.

In the final chapter, I demonstrated that this conception of spiritual exercises fits perfectly with what Epictetus has to say about the similarities between the philosopher and the athlete. I also argued that conceiving of Epictetus' combination of theory and spiritual exercises as being a somehow tedious or somehow lesser form of progress than rational argument alone could provide is unjustified. 


\section{Bibliography:}

Aristotle. "Nicomachean Ethics” In Aristotle: The Complete Works. Trans W. D. Ross. Charlottesville, Virginia, USA: InteLex Corporation, 1992. Past Masters. Web. March $11^{\text {th }} 2015$.

Baltzly, Dirk, "Stoicism", The Stanford Encyclopedia of Philosophy, Edward N.

Zalta (ed.) (Spring 2014 Edition): Web. September $20^{\text {th }} 2015$.

Bobzein, Susanne. "Stoic Logic", The Cambridge Companion to the Stoics, Brad Inwood (ed.). Cambridge: Cambridge University Press, 2003. 85-123. Print.

Braicovich, Rodrigo Sebastián. "Critical Assent, Intellectualism, and Repetition in Epictetus" Apeiron: A Journal for Ancient Philosophy and Science 45.4 (2012): 314337. Web. September $10^{\text {th }} 2015$.

Brennan, Tad. "Stoic Moral Psychology", The Cambridge Companion to the Stoics, Brad Inwood (ed.). Cambridge: Cambridge University Press, 2003. 257-294. Print.

Brennan, Tad. The Stoic Life: Emotions, Duties, and Fate. Oxford: Oxford University Press, 2005. Carleton University Library. Web. October $12^{\text {th }} 2015$.

Cooper, John M. "The Emotional Life of the Wise," in Southern Journal of Philosophy, 43, (2005): 176-218. Web. October $21^{\text {st }} 2015$.

----. "The Relevance of Moral Theory to Moral Improvement in Epictetus", The Philosophy of Epictetus, Theodore Scaltsas and Andrew S. Mason (ed). Oxford: Oxford University Press, 2007. 10-20. Carleton University Library. Web. November $5^{\text {th }} 2015$. 
Dent, J.M. "Introduction", The Discourses, The Handbook, Fragments. North Clarendon, U.S.A: $\quad$ The Orion Publishing Group, 1995. vii-xix. Print.

----. "Notes on Translation", The Discourses, The Handbook, Fragments. North

Clarendon, U.S.A: The Orion Publishing Group, 1995. xxiii-xxiv. Print.

Dobbin, Robert. "Introduction", Discourses and Selected Writings. London, U.K.:

Penguin Books, 2008. Print.

Epictetus. The Discourses. The Handbook, Fragments. Trans. Robin Hard. North Clarendon, U.S.A: The Orion Publishing Group, 1995. Print.

----. Discourses and Selected Writings. Trans. Robert Dobbin. London, U.K: Penguin Books, 2008. Print.

Gill, Christopher. "Did Chrysippus Understand Medea?”. Phronesis 28.2 (1983): 136149. Web. November $20^{\text {th }} 2015$.

Hadot, Pierre. Philosophy as a Way of Life. Ed. Arnold L. Davidson. Malden, USA:

Blackwell Publishers, 1998, Print.

Hankinson, R.J. “Stoic Epistemology”, The Cambridge Companion to the Stoics, Brad Inwood (ed.). Cambridge: Cambridge University Press, 2003. 59-84. Print.

Hijmans, B.L.. Askesis. Notes on Epictetus' Educational System (Assen: Van Gorcum \& Comp) 1959. Carleton University Library. Web. September $26^{\text {th }} 2015$.

Johnson, Brian E. The Role Ethics of Epictetus: Stoicism in Ordinary Life. Plymouth, U.K.: Lexington Books, 2014, Print.

Inwood, Brad. Ethics and Human Action in Early Stoicism. Oxford: Oxford University Press, 1985, Print. 
---- "Introduction: Stoicism, An Intellectual Odyssey", The Cambridge Companion to the Stoics, Brad Inwood (ed.). Cambridge: Cambrdige University Press, 2003. 1-6.

Print.

Irvine, William Braxton. A Guide to the Good Life: The Ancient Art of Stoic Joy. New York: Oxford University Press, 2009. Print

Long, A. A. Epictetus. Oxford University Press, 2002. Print.

---- 1996a. "Freedom and Determinism in the Stoic Theory of Human Action," Anthony

A. $\quad$ Long, ed., Problems in Stoicism (London: Athlone Press) 173-99. Print.

---- 1996b. "Representation and the Self in Stoicism," Stoic Studies (Berkeley: University of California Press) 264-84. Print.

Nussbaum, Martha Craven. The Therapy of Desire: Theory and Practice in Hellenistic Ethics. Princeton, N.J: Princeton University Press, 1994. Print.

---- 2001. Upheavals of Thought: The Intelligence of Emotions. New York; Cambridge: Cambridge University Press. Print.

Plato. "Republic" In The Dialogues of Plato. Trans Benjamin Jowett. Charlottesville, Virginia, USA: InteLex Coroporation, 1992. Past Masters. Web. March $11^{\text {th }} 2015$.

Roskam, Geert. On the Path to Virtue: The Stoic Doctrine of Moral Progress and Its Reception in (Middle-) Platonism. Leuven, Belgium: Leuven University Press, 2005. Web. November $1^{\text {st }} 2015$.

Salles, Ricardo. 2007. "Epictetus On Moral Responsibility for Precipitate Action," Christopher Bobonich and Pierre Destrée, eds., Akrasia in Greek 
Philosophy. From Socrates to Plotinus (Leiden: Brill) 249-55. Web. October 21 ${ }^{\text {st }}$ 2015.

Sellers, John. "Stoic Practical Philosophy in the Imperial Period" in Bulletin of the Institute of Classical Studies. Volume 50, Issue 94P1, Pages 115-140, June 2007. Web. September $\quad 17^{\text {th }} 2015$.

Sharpe, Matthew. "How It's Not the Chrysippus You Read: On Cooper, Hadot, Epictetus and stoicism as a Way of Life" in Philosophy Today 58.3, Pages 367-392, Summer 2014. Web. December $1^{\text {st }} 2015$.

Sherman, Nancy. Stoic Warriors: The Ancient Philosophy Behind the Military Mind. New York: Oxford University Press, 2005. Print.

Stephens, Williams O. "The Roman Stoics on Habit" in A History of Habit: From Aristotle to Bourdieu, Tom Sparrow Adam Hutchinson eds. Plymouth U.K.: Lexington Books. 2013. 37-64. Web. November $22^{\text {nd }} 2015$. 